\title{
Modelling the impacts of EU countries' electric car deployment plans on atmospheric emissions and concentrations
}

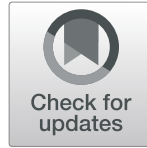

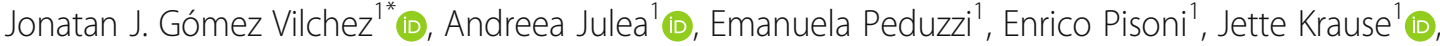 \\ Pelopidas Siskos ${ }^{2}$ and Christian Thiel ${ }^{1}$ (i)
}

\begin{abstract}
The purpose of this work is to quantify key environmental impacts of electric vehicles deployment in the European Union. This is achieved by soft-linking three models (PRIMES-TREMOVE, DIONE and SHERPA) to explore a base and an alternative scenario. The alternative scenario draws on the assessment of the national policy frameworks for alternative fuels infrastructure requested by the Directive (2014/94/EU). Five environmental indicators are examined: tailpipe $\mathrm{CO}_{2}, \mathrm{NO}_{x}$ and $\mathrm{PM}_{2.5}$ emissions as well as $\mathrm{NO}_{2}$ and $\mathrm{PM}_{2.5}$ urban background concentrations. By 2030, car travel activity is simulated to generate ca. $425 \mathrm{MtCO}_{2} /$ year in the EU28 under the alternative scenario. Compared to the base scenario, electric vehicles contribute to a $3 \%$ reduction in tailpipe $\mathrm{CO}_{2}$ emissions. Only two countries attain $\mathrm{CO}_{2}$ emission reductions greater than $10 \%$ in the model. The need for a higher level of policy ambition towards the deployment of less polluting vehicles in Europe is highlighted as a conclusion.
\end{abstract}

Keywords: Electro-mobility, Scenario analysis, Greenhouse gas emissions, Urban background air pollution, Passenger road transport

\section{Introduction}

To meet its commitments in the context of the 21st Conference of the Parties to the United Nations Framework Convention on Climate Change that took place in Paris in 2015, the European Union (EU) ${ }^{1}$ aims at reducing its transport greenhouse gas (GHG) emissions by at least $60 \%$ between 1990 and 2050 [23, 26] (see Table 1). Since the European transport sector emitted 851 megatonnes of carbon dioxide equivalent $\left(\mathrm{MtCO}_{2 \mathrm{eq}}\right)$ in 1990 [17], this translates into a maximum value of 340 $\mathrm{MtCO}_{2 \text { eq }}$ in 2050. To pursue this goal, European legislation is in place. An example is the Directive (2014/94/ $\mathrm{EU})$ on the deployment of alternative fuels infrastructure (henceforth, the Directive), which requested that

\footnotetext{
${ }^{1}$ For EU country codes, see http://ec.europa.eu/eurostat/statisticsexplained/index.php/Glossary:Country_codes.
}

\footnotetext{
* Correspondence: Jonatan.Gomez-Vilchez@ec.europa.eu

${ }^{1}$ European Commission, Joint Research Centre (JRC), Via E. Fermi, 2749 Ispra, VA, Italy

Full list of author information is available at the end of the article
}

Member States notify their National Policy Frameworks (NPFs) to the European Commission [24].

In mitigation strategies, road transport plays a crucial role, since it is responsible for $72.9 \%$ of transport GHG emissions and the main source of $\mathrm{NO}_{\mathrm{x}}$ emissions in Europe [18]. Cars account for $44.4 \%$ of total transport GHG emissions [17]. These vehicles are also a contributor to air pollution, which is harmful to the ecosystem and human health. EEA [19] estimated that over 400,000 premature deaths in Europe in 2012 can be attributed to air pollution. More recently, EEA [15] claimed that 391, 000 and 76,000 premature deaths in 2015 are respectively attributable to $\mathrm{PM}_{2.5}$ and $\mathrm{NO}_{2}$ exposure in the EU28 (even if these impacts cannot be simply aggregated, as this may lead to double counting).

This study focuses on passenger cars with different powertrain technologies. In this paper, the terms electric cars and electric vehicles (EVs) are used interchangeably and refer to battery electric vehicles (BEVs), plug-in hybrid electric vehicles (PHEVs) and fuel cell electric vehicles (FCEVs). 
Table 1 Key acronyms used in this paper

\begin{tabular}{ll}
\hline Acronym & Term \\
\hline $\mathrm{BEV}$ & Battery electric vehicle \\
$\mathrm{CNG}$ & Compressed natural gas \\
$\mathrm{CO}_{2}$ & Carbon dioxide \\
$\mathrm{EU}$ & European Union \\
$\mathrm{FCEV}$ & Fuel cell electric vehicle \\
$\mathrm{GHG}$ & Greenhouse gas \\
$\mathrm{LNG}$ & Liquefied natural gas \\
$\mathrm{PM}$ & Particulate matter \\
$\mathrm{NH}_{3}$ & Ammonia \\
$\mathrm{NMVOC}$ & Non-methane volatile organic compound \\
$\mathrm{NO}_{2}$ & Nitrogen dioxide \\
$\mathrm{NO}_{x}$ & Nitrogen oxides \\
$\mathrm{NPF}^{\mathrm{P}}$ & National policy framework \\
$(\mathrm{PHEV}$ & (Plug-in) hybrid electric vehicle \\
$(\mathrm{RE}) \mathrm{EV}$ & (Range extender) electric vehicle \\
$\mathrm{SO}$ & Sulphur oxides \\
$\mathrm{TEN}_{\mathrm{X}} \mathrm{T}$ & Trans-European Transport Network \\
\hline &
\end{tabular}

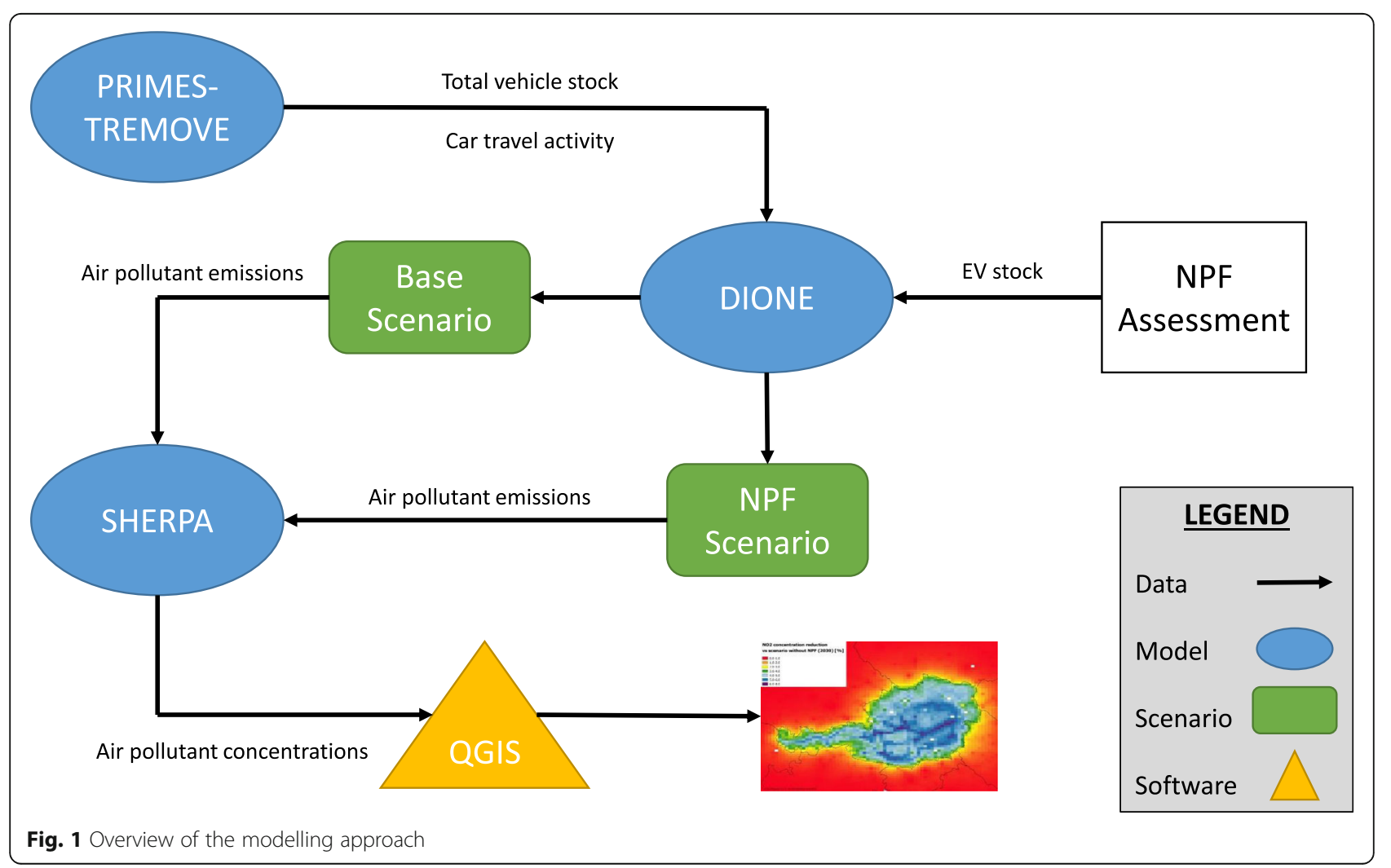

The objective of this work is to quantify key environmental impacts of EV deployment in the EU28 until 2030 taking into account the NPFs on the Directive developed by the EU Member States. Other policy initiatives adopted by the European Commission in the context of the 2017 Mobility Packages are beyond the scope of this paper. Their impact on the uptake of EVs is thus not reflected in this paper. Within the scope of analysis are GHG emissions as well as air pollutant emissions and concentrations.

The structure of the paper is as follows: Section 2 explains the modelling approach; Section 3 describes the data; in Section 4, two scenarios are introduced; Section 5 shows the key model output; conclusions are drawn in Section 6.

\section{Methods and models}

\subsection{Overview of the modelling approach}

Figure 1 shows a stylised overview of the modelling approach, highlighting the model soft-linkages. 'Soft-coupling' designates the exchange of a limited set of indicators between two models which are complementary in context or representation. Soft-coupling implies also that the two models may iterate, if necessary, to ensure that the feedback loop is closed. In contrast to this modelling approach, hard-coupling would entail model integration into a single, unified framework. As can be 
seen in Fig. 1, the first linkage is made from PRIMESTREMOVE to DIONE and the second model coupling from DIONE to SHERPA. The set of indicators exchanged are total vehicle stock and car travel activity as well as air pollutant emissions, respectively. The modelling strategy of soft-linking is challenging but may be beneficial (see Krook-Riekkola et al. [38] for a discussion in the field of energy). As can be seen, the modelling exercise comprises three models (PRIMES-TREMOVE, DIONE and SHERPA) and a geographic information system software (QGIS).

The PRIMES-TREMOVE and the DIONE models are complementary models, which feature some common attributes. PRIMES-TREMOVE is an energy economic model for the transport sector and is part of the main PRIMES model, which simulates the overall energy system. The transport demand simulated in PRIMESTREMOVE is based on the microeconomic theory and features a degree of engineering detail as regards the vehicle technologies. The model also handles, explicitly, policies related to the promotion of alternative fuels and low or zero emission vehicles (which is the scope of this paper). On the other hand, the DIONE model is a very detailed engineering model which calculates a larger (than PRIMES-TREMOVE) set of air pollutant emissions, based on technical specifications of vehicles' powertrains and engine sizes. The two models are linked to develop the base scenario. However, only the DIONE model was used to quantify the NPF scenario, using as input data from the NPF assessment. On top of this, for the purposes of this specific paper, the aim was to scale down the pollutant emissions at a more refined geographical scale. Specifically, the SHERPA model needs the following air pollutant emissions as inputs: nitrogen oxides $\left(\mathrm{NO}_{\mathrm{x}}\right)$, non-methane volatile organic compounds (NMVOC), ammonia $\left(\mathrm{NH}_{3}\right)$, particulate matter $\left(\mathrm{PM}_{2.5}\right)$, and sulphur oxides $\left(\mathrm{SO}_{\mathrm{x}}\right)$. While PRIMES-TREMOVE output was available for $\mathrm{NO}_{\mathrm{x}}, \mathrm{PM}_{2.5}$ and $\mathrm{SO}_{\mathrm{x}}$, the DIONE model additionally provided the NMVOC and $\mathrm{NH}_{3}$ emissions, which were necessary for the analysis. Hence, the suite of models employed (i.e. PRIMESTREMOVE, DIONE and SHERPA) ensures a consistent data transfer between the models.

The core model used in this study is the DIONE Fleet Impact Model (henceforth DIONE). Two streams of information feed this model: projections from PRIMESTREMOVE and data from the NPF assessment (see Section 3). To accomplish the data exchange, an Excel template was created. As a result of processing this information in DIONE, two scenarios were constructed (see Section 4).

The modelling exercise can be summarised as follows: projections of car stock and its composition as well as travel demand are combined with consumption functions and fuel efficiency values to estimate energy consumption, in turn used together with emission factors to calculate emissions in each Member State until 2030. The change in emissions between scenarios is used to estimate the consequent change in urban background concentrations of air pollutants. In the next sections, all the models introduced in Fig. 1 will be briefly presented.

\subsection{Description of the PRIMES-TREMOVE model}

The PRIMES energy system model [4] simulates market equilibrium solutions for energy demand and supply in the EU. PRIMES has been developed and maintained by E3MLab/Institute of Communication and Computer Systems of the National Technical University of Athens. The sub-model of the PRIMES energy system model, which simulates in detail the transport sector and is relevant to this work, is called PRIMES-TREMOVE.

PRIMES-TREMOVE simulates the transport sector as a market equilibrium problem where demanders and suppliers, including self-supply behaviour for the users of private cars, are modelled as individual agents. The model projects the evolution of demand for passengers and freight transport by transport mode and transport mean. It is a dynamic system of multi-agent choices under several constraints, which are not necessarily binding simultaneously. It has a modular structure, featuring a module projecting demand for transport services for passenger and freight mobility and a supply module deriving ways of meeting the demand. The supply module projects the optimum technology and fuel mix to produce transport services which meet demand. It includes a vehicle stock sub-module which considers stock of transport means inherited from previous time periods and determines the necessary changes to meet demand. PRIMES-TREMOVE tracks vehicle vintages and formulates the dynamics of vehicle stock turnover by combining scrapping and new registrations.

Three private cars-related key variables/output from the PRIMES-TREMOVE model are employed in this exercise, namely: vehicle stock, transport activity and final energy demand. In PRIMES-TREMOVE, the stock of private cars is disaggregated by powertrain and size (small, medium, big). In total, nine powertrains are modelled including a distinction of hybrid and plug-in hybrid vehicle powertrains into gasoline and diesel powered [46]. The horizon of the model is 2050; for the purposes of the present paper, we focused on the 2030 horizon. PRIMES-TREMOVE model outputs are available on 5 -year time steps.

The detailed documentation of the entire PRIMES model is available in E3MLab [9]. A detailed presentation and confirmation of the PRIMES model is provided in Capros et al. [4]. Most recent applications of the PRIMES and PRIMES-TREMOVE models available to the scientific community are presented in Capros et al. [3] and Siskos et al. [47]. 


\subsection{Description of the DIONE model}

DIONE is a tool that allows analysing scenarios of European road vehicle stock, activity, energy consumption and emissions (GHGs and air pollutants) up to 2050 [48]. It was developed for assessing transport and energy (policy) options, such as fleet emission targets, vehicle technology transitions, alternative fuels mixes, scrappage schemes, etc. It builds on a detailed representation of road vehicle types and powertrains, their activities and efficiencies. Seven categories of conventional passenger cars are available, classified by fuel type and engine size. Moreover, there are eight categories of electrified cars (hybrid electric vehicle (HEV), PHEV, range-extender electric vehicle (REEV), BEV and FCEV) as well as seven categories of flex-fuelled vehicles (gasoline-compressed natural gas (CNG), gasoline-liquefied petroleum gas and gasoline-ethanol 85).

DIONE contains a calibrated baseline, which is based on the country-specific stock and activity data collected in the EU research project TRACCS (see [54]). The original baseline was taken forward following the trends of the EU Reference Scenario 2012. Within the context of this study, the baseline was updated to EU Reference Scenario 2016 as described in Section 4. Four car sizes are included in DIONE: tiny (represented by an engine capacity of $<0.8 \mathrm{l})$, small $(0.8-1.4 \mathrm{l})$, medium $(1.4-2.0 \mathrm{l})$ and large $(>2.0 \mathrm{l})$. For internal combustion engine vehicles, estimation of energy consumption and emissions in DIONE is based on COPERT 4 [20]. For BEVs, the energy consumption factor was estimated from real drive data collected in the context of the Green eMotion project [30]. The DIONE fleet impact model can be employed to run scenarios on EU Member State level or aggregates thereof. The model is run for the period 2017-2030, with annual resolution.

DIONE is flexible enough to allow soft-linkages with other models (see Harrison et al. [32] for an example of DIONE being soft-linked with another model not covered in this paper). In this work, DIONE is soft-linked with PRIMES-TREMOVE and SHERPA. It also receives input data from the NPF assessment, i.e. future new vehicle fleet composition according to Member States' electric car deployment plans, which is used as a basis for calculating emissions under the alternative scenario.

Further details on DIONE can be found in Krause et al. [37].

\subsection{Description of the SHERPA model}

The Screening for High Emission Reduction Potential on Air (SHERPA) model $[5,43,52]$ quantifies the relationships between emissions and urban background concentration levels, mimicking the behaviour of a complex full air quality model. The SHERPA model has been created both to support regional/local decision makers to design air quality plans, and to support the European
Commission for Impact Assessment evaluations. It is distributed with default data covering Europe at $\sim 7 \times 7 \mathrm{~km}^{2}$ spatial resolution, and allows decision makers to work on any European domain, without the need to perform complex scientific/technical tasks beforehand. The model is based on linearity assumptions, which have been tested and confirmed in previous works [51,53]. Validation of the SHERPA model can be found in Pisoni et al. [43].

DIONE generates values for total $\mathrm{NO}_{\mathrm{x}}$, NMVOC, $\mathrm{NH}_{3}, \mathrm{PM}$ and $\mathrm{SO}_{\mathrm{x}}$ emissions for each Member State analysed, expressed in terms of percent reductions between scenarios. Once these results are introduced into SHERPA as inputs, the model delivers urban background concentrations of air pollutants, namely nitrogen dioxide $\left(\mathrm{NO}_{2}\right), \mathrm{PM}_{2.5}$ and $\mathrm{PM}_{10}$. More specifically, for $\mathrm{NO}_{2}$ modelling, SHERPA simulates at first the link between $\mathrm{NO}_{\mathrm{x}}$ emissions and $\mathrm{NO}_{\mathrm{x}}$ concentrations; and then converts $\mathrm{NO}_{\mathrm{x}}$ concentrations to $\mathrm{NO}_{2}$ concentrations using the relation as in Düring et al. [8]. For $\mathrm{PM}_{2.5}$, precursor emission reductions (as primary PM and other precursor emissions) are directly linked to $\mathrm{PM}_{2.5}$ concentrations. In the modelling of $\mathrm{PM}_{2.5}$, both primary and secondary $\mathrm{PM}_{2.5}$ components are taken into account.

In order to calculate atmospheric dispersion, the emissions are regionalized within the Member States as follows: initially, the emissions per Member State and sectors are derived from the GAINS model [35]. Then, sector-specific proxies are applied to compute the fraction of Member State level emissions to be associated to each cell (i.e. traffic emissions are distributed only on road-related grids, residential heating is linked to buildup, etc.). More details on the applied methodology can be found in Trombetti et al. [55].

These results on air pollutant concentrations can be further processed to generate maps. To do so, we used the open-source geographic information system software available from QGIS [44]. In this way, a geospatial representation of the results of the modelling exercise is given.

\section{Data from the NPF assessment}

The Directive aims at facilitating the market uptake of alternative fuels vehicles and vessels as well as infrastructure build-up. The Directive set out minimum infrastructure requirements for alternative fuels. The NPF assessment refers to the evaluation of the EU Member States' NPFs notified to the European Commission between 2016 and 2017, as requested by the Directive. ${ }^{2}$ In their NPFs, Member States had to communicate infrastructure targets for: electricity and CNG in urban/

\footnotetext{
${ }^{2}$ The exceptions are EL, MT, RO and SI, because they had not officially notified their NPFs by 31 October 2017, the time that this assessment was conducted.
} 
suburban and other densely populated areas by the end of 2020; for CNG along the Trans-European Transport Network (TEN-T) core network, liquefied natural gas (LNG) at the TEN-T core network maritime ports and LNG for heavy duty vehicles along the TEN-T core network by the end of 2025 as well as LNG at TEN-T core network inland ports by the end of 2030 and, optionally, for hydrogen in 2025 [24]. In most cases, Member States' plans for the build-up of infrastructure in the NPF were presented alongside information on their estimates regarding the market penetration of alternative fuels vehicles. As with infrastructure, estimates of EVs were mandatory only in 2020. From this data, the estimates on EV deployment were collected for each country. Table 2 shows our dataset as a result of the NPF assessment (see Research data in Additional file 1). As can be seen, there are substantial differences between countries (2\% to $38 \%$ ) in $2030 \mathrm{EV}$ shares, at least with respect to total car stock in 2017.

Some NPFs provided more than one estimate for certain years. Unless it was clear there was a middle estimate, the average of the provided estimates for a given year was calculated. These data were then used to construct the alternative scenario. Data from the European Alternative Fuels Observatory website [10] related to the current situation was also considered to check potential inconsistencies between the models and the NPF assessment.

\section{Scenarios construction}

To deal with uncertainty, the scenarios method in which alternative future pathways are outlined is adopted (see Dieckhoff [6] for a comprehensive treatment of energy scenarios). In this modelling exercise, two scenarios were constructed: the base scenario and an alternative scenario named NPF scenario. The key difference between them lies in the car stock composition. While the aggregated or total car stock remains the same in both scenarios, the disaggregated or car stock by powertrain differs. To construct the base scenario, the model output of PRIMES-TREMOVE is taken as an input for DIONE. To construct the NPF scenario, the results of the NPF assessment are used as an input for DIONE. Then, DIONE calculates levels of emissions for both scenarios. Throughout the modelling exercise, an Excel template was exploited to transfer information among models.

\subsection{Base scenario}

The base scenario was constructed using the EU Reference Scenario 2016 [12] as a starting point and removing any incentives for alternative fuels at the Member State level. The base scenario includes the $\mathrm{CO}_{2}$ emissions targets on car manufacturers for the period until 2021 but does not include the recent targets set on car manufacturers for 2025 and 2030. The fact that the same model (PRIMES-TREMOVE) was used to quantify both the EU Reference Scenario 2016 and the base scenario ensures consistency. PRIMES-TREMOVE follows a microeconomic approach where decision makers for the passenger transport sector seek to maximize their utility under

Table 2 Total car stock in 2017 and NPF data on EV stock estimates for 2020, 2025 and 2030, by country

\begin{tabular}{|c|c|c|c|c|c|c|c|c|c|}
\hline \multirow[t]{2}{*}{ Country } & \multirow{2}{*}{$\begin{array}{l}\text { Total stock } \\
2017\end{array}$} & \multicolumn{3}{|l|}{ EV stock } & \multirow[t]{2}{*}{ Country } & \multirow{2}{*}{$\begin{array}{l}\text { Total stock } \\
2017\end{array}$} & \multicolumn{3}{|l|}{ EV stock } \\
\hline & & 2020 & 2025 & 2030 & & & 2020 & 2025 & 2030 \\
\hline AT & $4,898,578$ & 119,512 & 717,262 & $1,315,012$ & IE & $2,142,390$ & 25,000 & 262,500 & 823,005 \\
\hline $\mathrm{BE}$ & $5,785,447$ & 86,663 & $n / f$ & $n / f$ & IT & $37,876,138$ & 88,500 & 114,500 & $2,987,500$ \\
\hline BG & $2,770,615$ & 35,050 & 70,400 & 130,900 & $\mathrm{LT}$ & $1,356,987$ & 1,200 & $n / f$ & $n / f$ \\
\hline$C Y$ & 526,617 & 1,050 & $n / f$ & $n / f$ & LU & 403,282 & 40,000 & 44,000 & 48,000 \\
\hline$C Z$ & $5,538,222$ & 17,000 & 100,000 & 250,000 & LV & 689,536 & 747 & $n / f$ & $n / f$ \\
\hline DE & $46,474,594$ & $1,000,215$ & $n / f$ & $n / f$ & MT & 291,664 & $\mathrm{n} / \mathrm{a}$ & $\mathrm{n} / \mathrm{a}$ & $\mathrm{n} / \mathrm{a}$ \\
\hline DK & $2,530,047$ & 30,689 & 65,689 & $n / f$ & $\mathrm{NL}$ & $8,373,244$ & 142,120 & $n / f$ & $n / f$ \\
\hline $\mathrm{EE}$ & 725,944 & 1,257 & $n / f$ & $n / f$ & $P L$ & $22,503,579$ & 76,898 & $1,029,470$ & $n / f$ \\
\hline EL & $5,235,928$ & $\mathrm{n} / \mathrm{a}$ & $\mathrm{n} / \mathrm{a}$ & $\mathrm{n} / \mathrm{a}$ & PT & $5,059,472$ & 14,000 & 45,000 & 80,000 \\
\hline ES & $23,500,401$ & 94,500 & $1,347,500$ & $2,600,500$ & $\mathrm{RO}$ & $5,155,000$ & $\mathrm{n} / \mathrm{a}$ & $\mathrm{n} / \mathrm{a}$ & $\mathrm{n} / \mathrm{a}$ \\
\hline $\mathrm{Fl}$ & $3,398,937$ & 22,000 & 106,000 & 263,000 & SE & $4,844,823$ & $n / f$ & $n / f$ & $n / f$ \\
\hline FR & $32,005,986$ & 960,000 & $2,400,000$ & $n / f$ & SI & $1,117,935$ & n/a & n/a & $\mathrm{n} / \mathrm{a}$ \\
\hline $\mathrm{HR}$ & $1,596,087$ & $n / f$ & $n / f$ & $n / f$ & SK & $2,223,117$ & 10,000 & 20,000 & 35,000 \\
\hline $\mathrm{HU}$ & $3,471,997$ & 21,000 & 101,450 & 181,900 & UK & $31,200,182$ & 413,585 & $n / f$ & $n / f$ \\
\hline
\end{tabular}

Source: based on Eurostat [28] and notified NPFs. ' $n / a^{\prime}$ refers to data 'not available' because the NPF was not notified on time (The exceptions are EL, MT, RO and SI, because they had not officially notified their NPFs by 31 October 2017, the time that this assessment was conducted). Total stock for IT and RO refer to 2016 and 2015, respectively. ' $n / f^{\prime}$ means data 'not found' in the NPF 
budget and other constraints. The new vehicle choice determines the mix of new vehicle technologies and fuels in the new vehicle registrations for each consecutive time period. Alternative vehicle technologies and fuels compete based on cost and other considerations in a Weibull discrete choice model. Hence, if the costs of EVs decrease, the relative market share of gasoline and diesel cars decreases based on the relative ratios of their cost performance. In the presence of $\mathrm{CO}_{2}$ targets for car manufacturers, shadow values apply in the cost of the various alternative options which do not comply with the target. The shadow values, which penalize vehicle options with high specific $\mathrm{CO}_{2}$ emissions (in $\mathrm{gCO}_{2} / \mathrm{km}$ ) ensure that the $\mathrm{CO}_{2}$ target is met. Low-emission vehicles such as EVs are favoured by the presence of $\mathrm{CO}_{2}$ targets on car manufacturers. In the absence of incentives for alternative fuels at the Member State level, battery cost reductions still lead to EV market uptake. The initial projections of car travel activity in PRIMES-TREMOVE and DIONE differ. As can be seen in Fig. 2, the original DIONE values, based on the 2012 version of the EU Reference Scenario, were systematically higher. To update them to the Reference Scenario 2016 projections, a correction was introduced by adjusting the average base mileage, measured in $\mathrm{km} / \mathrm{car}$. The results shown in Figs. 2, 3, 4, 5 and 6 are for the EU28, but country-specific calculations were also made.

There also was a discrepancy between DIONE original and Reference Scenario 2016 stock, with DIONE car stock lower than in Reference Scenario 2016. Our aim was to mimic in DIONE the evolution of the total car stock projected by current PRIMES-TREMOVE outputs. For this reason, the default values in DIONE were updated to the projections within the Reference Scenario 2016. As a result, both models ended up with the same total car stock projections (Fig. 2).
Because of its implications for energy demand and emissions, of interest in this modelling exercise is the disaggregation of the total car stock by powertrain. In the base scenario, the EU Reference Scenario private car stock projections 2018-2030 for each country were used. To ensure that the level of compatibility between both models was good enough to proceed further with the scenario analysis, assumptions had to be adopted (see Table 3). For instance, whereas PRIMES-TREMOVE disaggregates BEVs and FCEVs into three sizes, DIONE only represents these powertrains as medium-sized cars. We thus had to assume that the medium-sized PHEV stock can be used as a proxy for the average of small, medium and large PHEV stocks in PRIMES-TREMOVE. When faced with discrepancies in the units of measurement, adjustments to ensure dimensional consistency were also made.

When it comes to tank-to-wheel (i.e. tailpipe) $\mathrm{CO}_{2}$ emissions from cars, a gap between the PRIMESTREMOVE and the DIONE output remains after the DIONE model update (Fig. 3). Although energy demand in DIONE was slightly lower than in PRIMESTREMOVE (see Figure 11 in Appendix), the corresponding tailpipe $\mathrm{CO}_{2}$ emissions are moderately higher. This gap can be explained not only by the model differences highlighted in Table 3 but also by the role biofuels play in the two models. Equation 1 is used to calculate $\mathrm{CO}_{2}$ emissions from powertrain technologies which operate on blends of petroleum products and biofuels:

$$
C O_{2}=E F *(1-\beta) * E
$$

where $E F=$ emission factor of the respective petroleum product, $\beta=$ biofuel blend percentage (biofuel blending ratio), $E$ = energy consumption of the overall blended petroleum product and biofuel.

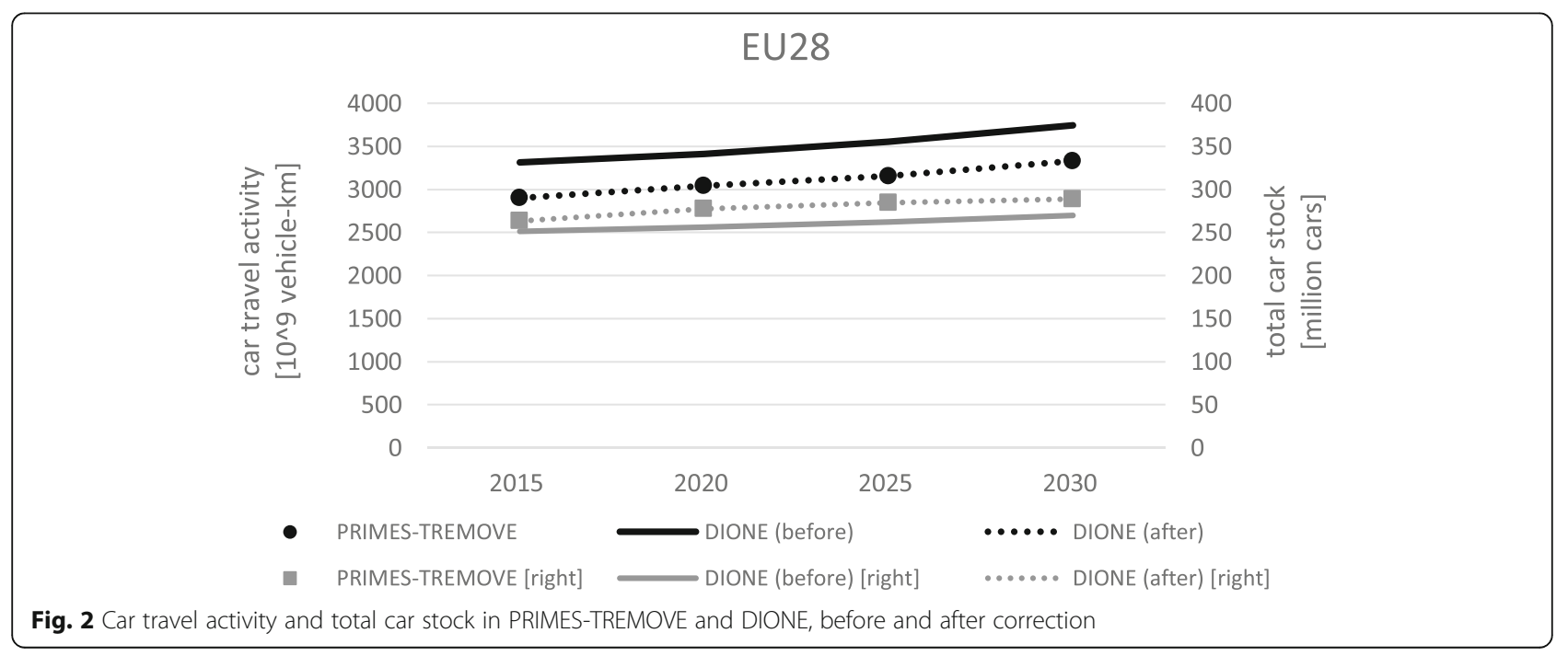




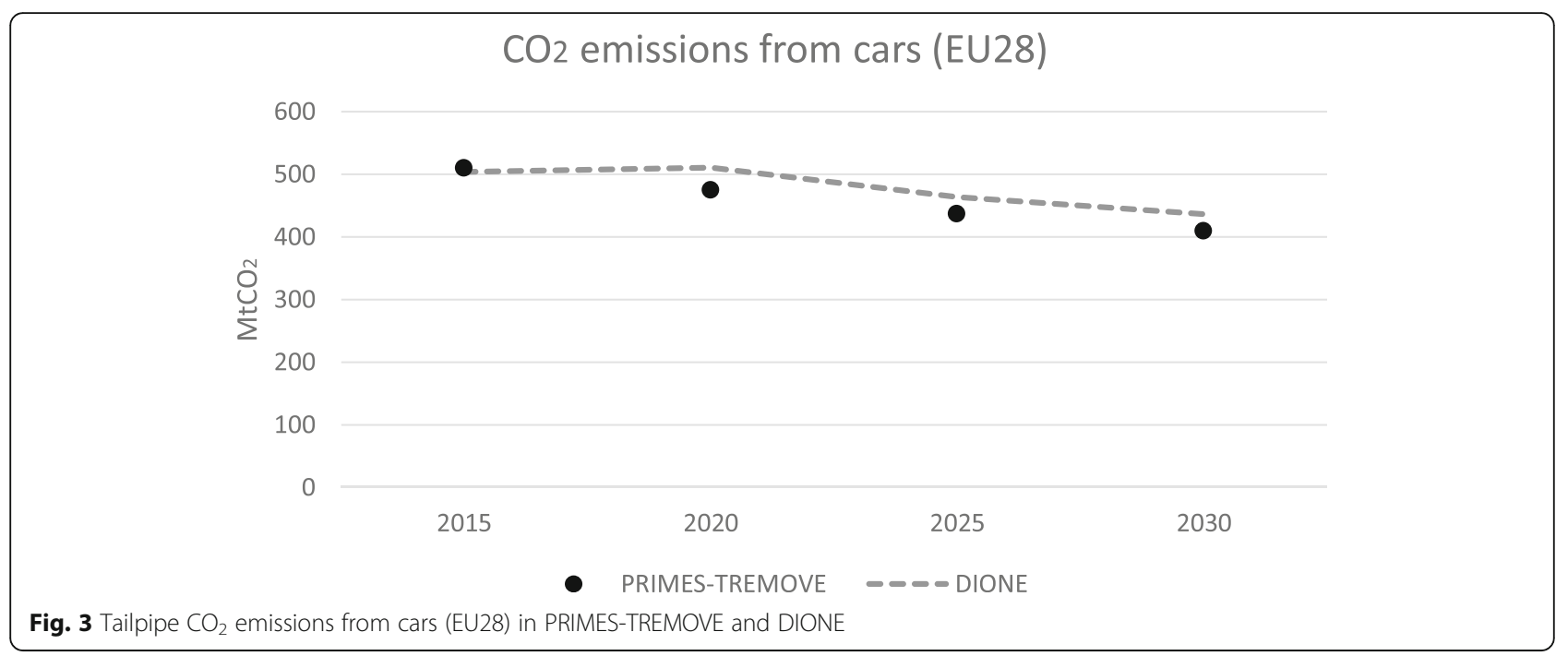

This convention draws from the concept of "carbon neutrality". Biofuels are considered as a carbon-neutral source of energy, stemming from the fact that biomass combustion releases the same amount of $\mathrm{CO}_{2}$ as was captured by the plant during its growth. The modelling follows this convention, as is also stated in the Fuel Quality Directive (see Annex IV, section C.13 in EU [27]). In quantitative terms, the car $\mathrm{CO}_{2}$ emissions mitigated through the use of biofuels in the EU28 are approximately $30 \mathrm{MtCO}_{2}$ in 2020, $28 \mathrm{MtCO}_{2}$ in 2025 and $27 \mathrm{MtCO}_{2}$ in 2030.

After the base scenario was simulated in DIONE, the NPF scenario was developed.

\subsection{NPF scenario}

The difference between the base and the NPF scenario is in the projected EV stock. Figure 4 shows the simulated spread between both scenarios at the EU28 level. As can be seen, the divergence in EV stock between scenarios increases as the simulation time horizon extends. In 2030, EV stock in the NPF scenario reaches ca. 18.7 million cars, compared to 11.8 million under the base scenario.

Our overarching goal when constructing this NPF scenario was to use the information provided by the Member States in their NPFs. It needs to be noted that the scenarios that each Member State elaborated for its NPF typically considered the specificity of each Member State. The data summarised in Table 2 was utilised to build this scenario. Three groups of countries can be distinguished:

1. Eleven countries for which NPF values are available for all the required years: AT, BG, CZ, ES, FI, HU, IE, IT, LU, PT and SK.

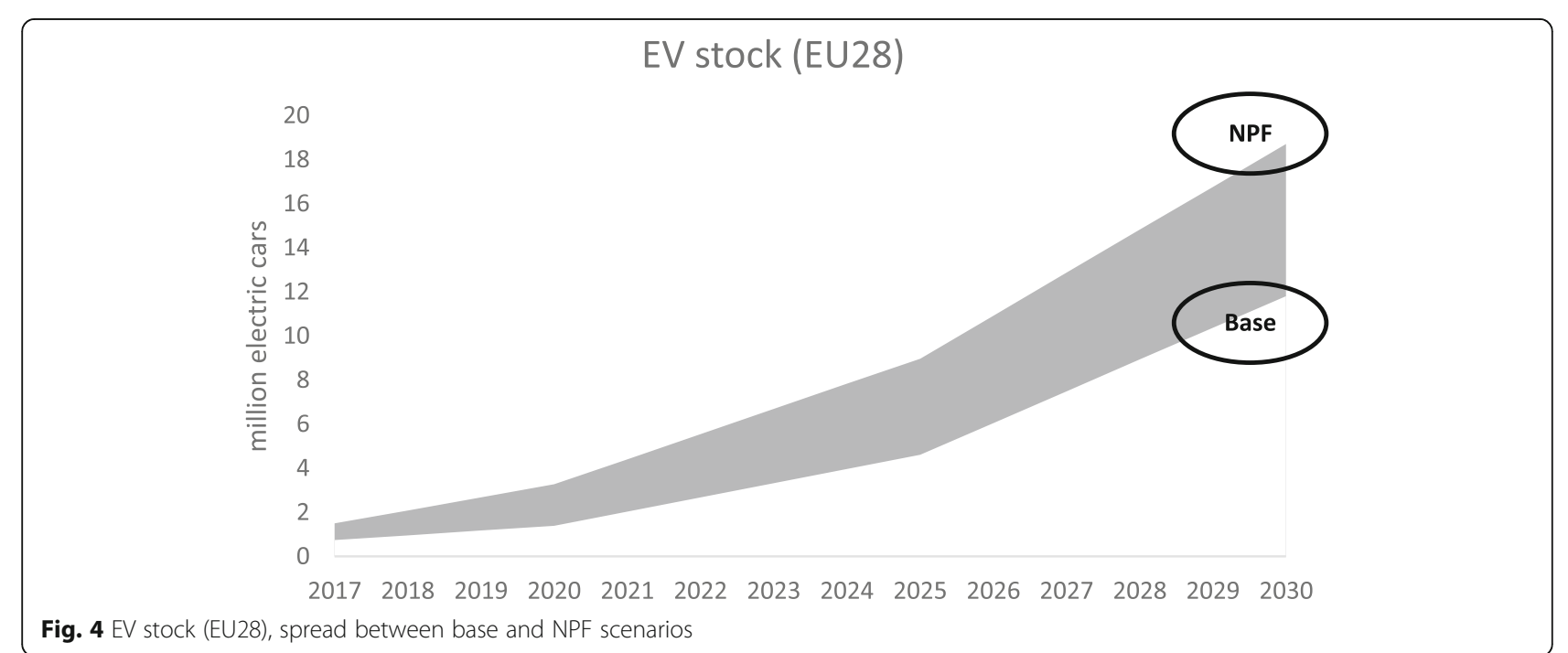




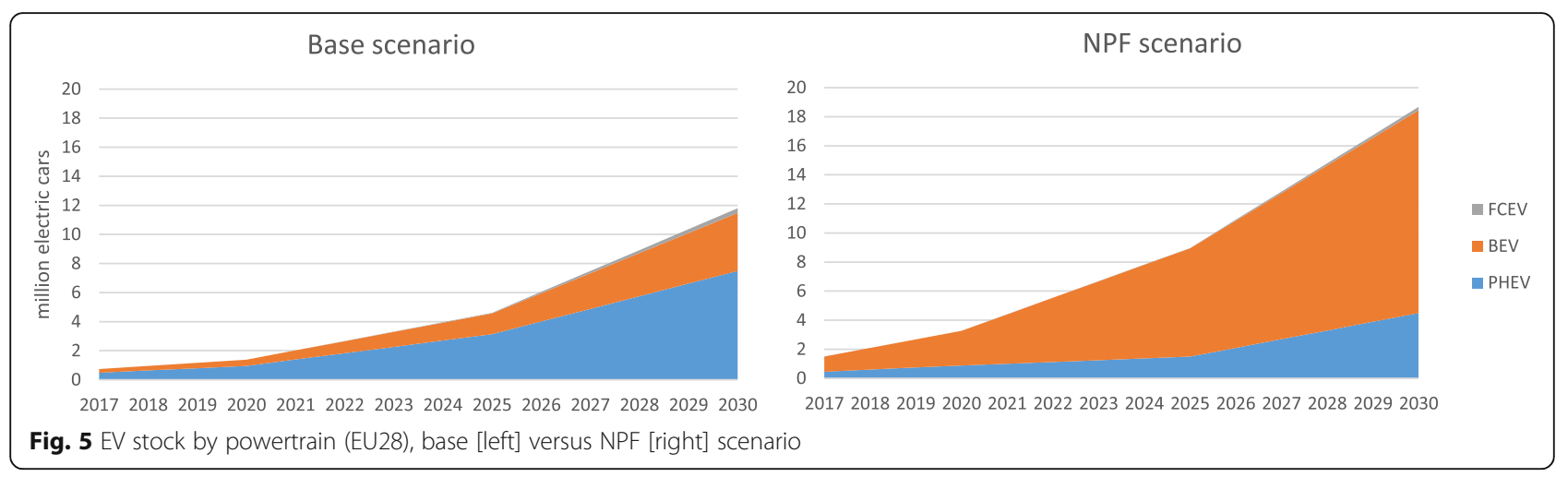

2. Eleven countries for which NPF values are available, but only until 2020 (BE, CY, DE, EE, LT, LV, NL and UK) or 2025 (DK, FR and PL).

3. Six countries for which NPF values are not available for any of the required years, either because they did not communicate any value in the NPF (the case of HR and SE) or because they did not notify their NPF by 31 October 2017 (recall footnote 2 ).

For the first group, the NPF values were incorporated in the modelling exercise. For these countries, EV market penetration is simulated to be higher in the NPF scenario than in the base scenario, with the exception of FI. The modelling in PRIMES-TREMOVE was influenced by the more ambitious EV stock estimate made earlier in the Impact Assessment, which was 35,000 EVs in use in 2020 [25]. However, the Finish government turned out to be more conservative $(22,000 \mathrm{EVs}$ in use in 2020) in its NPF.

Because of the missing observations, building the NPF scenario for the countries listed in the second and third groups required an additional assumption. The countries in the second group reported EV stock estimates until at least the year 2020 in their NPFs. On the other hand, the time horizon chosen for the modelling exercise extended until 2030. Several approaches to deal with this issue were identified at an early stage of the research design: (i) use average values of the first group, (ii) take into account socio-demographic characteristics, (iii) assume constant values of the EV stock beyond the last year for which an NPF value is available (i.e. 2020 or 2025, depending on the country); or (iv) adopt the values of the base scenario beyond the last available year. The first two were not tested in this study on the following grounds: (i) the average car stock of the first group is more than one million lower than the average EU28 car stock, (ii) the NPF values differ, often substantially, from the estimates calculated in EU [25], which had taken into account sociodemographic and economic aspects. The last two were tested (see Appendix). As expected, the third approach resulted in large divergences by 2030 , at least for some countries. For this reason, the fourth approach was preferred and reported in this paper.

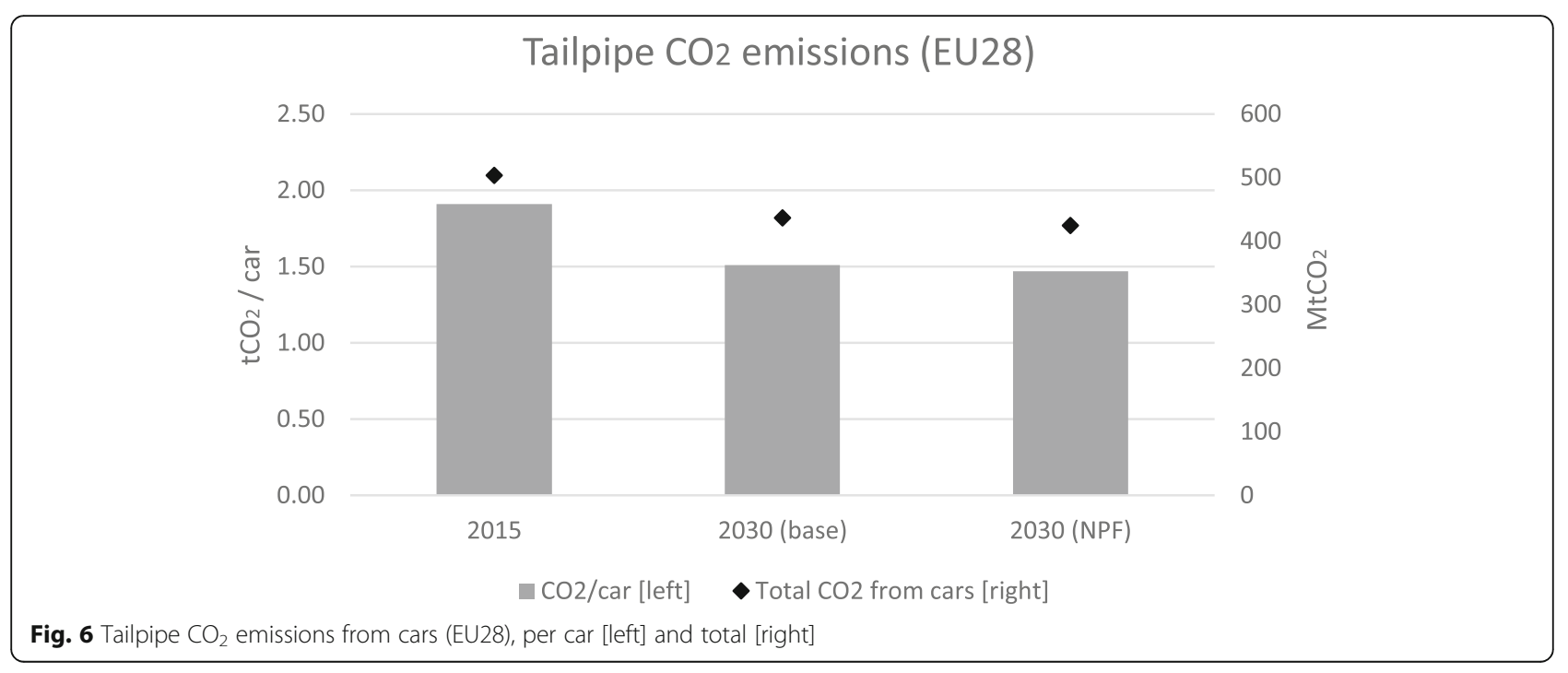


Table 3 Modellers' assumptions to address model differences

\begin{tabular}{ll}
\hline PRIMES - DIONE differences & Assumptions \\
\hline No $<0.8$ I car category in PRIMES. & The stock in DIONE is zero. \\
$\begin{array}{ll}\text { Mild hybrids are reported under } \\
\text { the conventional car categories in }\end{array}$ & The stock in DIONE is zero.
\end{tabular}
PRIMES .

REEVs are reported under the overall PHEV category in PRIMES ${ }^{\text {b. }}$

No small gasoline HEVs in DIONE.

Only medium-sized flexible fuel vehicles, diesel HEVs, PHEVs, BEVs and FCEVs in DIONE.

PRIMES runs on 5-year time steps $(2010, \ldots, 2050)$.

\section{The stock in DIONE is zero.}

The respective values for the medium-sized gasoline cars from PRIMES were utilised.

The respective values for the medium-sized car technologies from PRIMES were utilised.

Linear interpolation for intermediate years, performed in DIONE.

${ }^{a}$ Mild hybridisation is a technology option concerning the energy efficiency potential of conventional internal combustion engine technologies. It is included in the PRIMES-TREMOVE model, but not as a separate vehicle category

${ }^{b}$ REEVs are also implicitly included in PRIMES-TREMOVE as specific categories of the PHEVs (i.e. with higher electric ranges)

For the third group, given the absence of NPF data, the values of the base scenario were used. This implies that, for these six countries, the results of the base and NPF scenarios are equal (to some extent, the same occurs for the countries of the second group in either 2025 or 2030).

As indicated in Section 2.1, the quantification of the NPF scenario was done in DIONE. We assumed that each future EV stock estimate identified in the NPF assessment replaced a medium-sized conventional (gasoline or diesel) car. As a general rule, we assumed that two EVs replaced one gasoline and one diesel car. There were exceptions to this rule whenever we found a situation that would have led to a future negative stock of medium-sized conventional cars. This occurred with AT and IE. In the Austrian case, each EV was assumed to replace 0.7 diesel and 0.3 gasoline cars to avoid a negative stock of medium-sized gasoline cars. In the case of IE, each EV was assumed to replace 0.4 diesel and 0.6 gasoline cars to avoid a negative stock of medium-sized diesel cars.

Only FR and UK communicated in their NPFs a clear split between BEV and PHEV stock estimates. In the absence of this information, we assumed that EVs referred to BEVs. As a result, the base and NPF scenarios do not only differ in the total number of electric cars projected, but also on the relative shares of BEVs, PHEVs and FCEVs (see Fig. 5). The modelling decision not to assign a proportion to PHEVs and FCEVs requires justification. In the case of PHEVs, for the prospective car purchaser the main advantages of PHEVs over BEVs are driving range and refuelling/recharging time. Data from EAFO [10] suggests that the number of PHEV models available in the EU in 2017 was slightly higher than for BEV. For the German market at least, we found mixed evidence as to whether the purchase price of a PHEV is higher than that of its BEV counterpart: whereas the PHEV version of the Volkswagen Golf was found to be more expensive than its BEV counterpart [56], the Hyundai IONIQ PHEV was found to be cheaper than the BEV version [34]. However, we identified five reasons why these two advantages, both linked to the battery, might disappear in the future: (i) battery improvements (see Nitta et al. [40]) that lead to greater energy density and electric range favour BEVs; (ii) we expect the trend of battery cost reductions (see Nykvist and Nilsson [42]), which is more beneficial to BEVs, to continue in the next years; (iii) the deployment of ultrafast (i.e. up to $350 \mathrm{~kW}$ ) recharging stations (see e.g. Ionity [36]) has the potential to lower average recharging time; (iv) the impact the recent introduction of the worldwide harmonized light vehicles test procedure has had on PHEV sales and supply plans (see e.g. [1]); and (v) public awareness that PHEVs are low-emission cars while BEVs are zero tailpipe emission cars is likely to increase over time. Today, the leading EV markets are China and Norway, when measured respectively in total stock and sales market share. On the former BEVs accounted for $77 \%$ of the EV stock in 2017, on the latter for $64 \%$ [29]. With regards to FCEVs, the number of model offerings is at present very low, and restricted to the segment of large vehicles (see data from EAFO [10]). We assumed that this powertrain remains an unattractive option until 2030 due to uncertainty about (i) the cost evolution of key FCEV components (for the fuel cell system, see e.g. DOE [7]), and (ii) the required level of investment to guarantee an adequate network of hydrogen refuelling stations (for a cost estimate per station, see e.g. e-Mobil BW [21]). In recent research, BEVs are shown to clearly dominate over PHEVs and FCEVs in the future EU car market under various scenarios (see Figure 49 in EC [11]).

This and other aforementioned modelling assumptions, adopted in the light of missing or insufficient information available in several NPFs, are summarised in Table 4.

\section{Results for key environmental indicators and discussion}

The results of the modelling exercise are shown for five environmental indicators: GHG, $\mathrm{NO}_{\mathrm{x}}$ and $\mathrm{PM}_{2.5}$ emissions as well as $\mathrm{NO}_{2}$ and $\mathrm{PM}_{2.5}$ concentrations. At the EU28 level, both scenarios led to reductions in the absolute values of these variables between 2015 and 2030 (for tailpipe $\mathrm{CO}_{2}$ emissions, see Fig. 6). This is driven by the $\mathrm{CO}_{2}$ emission limits per kilometre established at EU level for 2021, which leads to more efficient conventional powertrains being used. Car travel activity is simulated to generate ca. $425 \mathrm{MtCO}_{2}$ /year in the EU28 under 
Table 4 Modelling assumptions to address inadequate information

\begin{tabular}{ll}
\hline NPF information & General assumption \\
\hline $\begin{array}{l}\text { More than one estimate of EV } \\
\text { stock was reported for a given } \\
\text { year. }\end{array}$ & $\begin{array}{l}\text { Average value calculated, in the } \\
\text { absence of a middle estimate. }\end{array}$ \\
$\begin{array}{l}\text { EV stock estimates for certain } \\
\text { years }(2020,2025,2030) \text { were not } \\
\text { available. }\end{array}$ & $\begin{array}{l}\text { Base scenario values assumed } \\
\text { beyond the last available year. }\end{array}$ \\
$\begin{array}{l}\text { Powertrain replacement not } \\
\text { reported. }\end{array}$ & $\begin{array}{l}\text { Two EVs replace two medium-sized } \\
\text { conventional cars: one gasoline and } \\
\text { one diesel (see text for exceptions). }\end{array}$ \\
$\begin{array}{l}\text { Type of EV not reported. } \\
\text { EV refers to BEV. }\end{array}$ \\
\hline
\end{tabular}

the alternative scenario in 2030. Compared to the base scenario, EVs contribute to a $3 \%$ reduction in tailpipe $\mathrm{CO}_{2}$ emissions from cars in that year. To bring this into perspective, the reduction translates into annual emissions of $1.51 \mathrm{tCO}_{2}$ per car in the base scenario and 1.47 $\mathrm{tCO}_{2}$ per car in the NPF scenario in 2030, down from $1.91 \mathrm{tCO}_{2}$ per car in 2015. Thus on a per car basis, tailpipe $\mathrm{CO}_{2}$ emissions are $21 \%$ lower in 2030 under the base scenario than in 2015 .

In the next two figures, only the results for the countries listed in the first group (cf. Section 4.2) are shown. Figure 7 shows the percentage change in EV stock (abscissa) in the NPF scenario with respect to the base scenario in 2030 plotted against the percentage change in tailpipe $\mathrm{CO}_{2}$ emissions (ordinate) between both scenarios in the same year, by country. In general, the simulated $\mathrm{CO}_{2}$ emission reductions are quite modest. Only two countries (AT and IE) are simulated to reduce their $\mathrm{CO}_{2}$ emissions by more than $10 \%$.

Overall, the chart seems to show a positive correlation between a higher EV stock deployment and a greater mitigation in $\mathrm{CO}_{2}$ emissions. Two observations (i.e. countries) deviate from this pattern: BG and PT. For the former, the simulated $\mathrm{CO}_{2}$ reduction is rather modest despite a relatively strong growth in EV stock. It should however be noted that EV stock in BG in 2030 (i) has the lowest value of this group of countries under the base scenario, and (ii) represents only $4 \%$ of total car stock (in contrast to $31 \%$ in IE and $24 \%$ in AT) under the NPF scenario. For PT, $\mathrm{CO}_{2}$ emissions are slightly higher under the NPF scenario. This result can be explained by the fact that the simulated stock of gasoline cars in PT turns out to be larger in the NPF than in the base scenario. The reason for this being that the future stock of medium-sized gasoline cars is declining in PRIMES-TREMOVE, in line with the dieselisation trend exhibited by this country [14], and the powertrain replacement rule applied under the NPF scenario (recall Section 4.2).

The case of FI is also remarkable: despite exceptionally simulating a lower EV stock in the NPF than in the base scenario $(-5 \%)$, the corresponding $\mathrm{CO}_{2}$ emissions are lower $(-0.4 \%)$. This can be explained by the fact that the share of BEVs among EVs is higher in the NPF scenario (see also Appendix).

Concerning air pollution mitigation, Fig. 8 shows the results of air pollutant, namely $\mathrm{NO}_{\mathrm{x}}$ and $\mathrm{PM}_{2.5}$, emission reductions. It is interesting to note that whereas in the model the highest reductions for $\mathrm{CO}_{2}$ (Fig. 7) were achieved in IE, AT outperforms in air pollutant emission reductions in 2030. The interpretation for this relates to the modelling decisions made for these countries, in an attempt to avoid negative stocks, as described in Section 4.2. In relative terms, more diesel cars were replaced in AT, which are known to have a larger effect on $\mathrm{NO}_{\mathrm{x}}$ emissions [57].

With regard to atmospheric concentrations, Figs. 9 and 10 show the simulated 2020 and 2030 reductions attained in the NPF scenario with respect to the base scenario for,

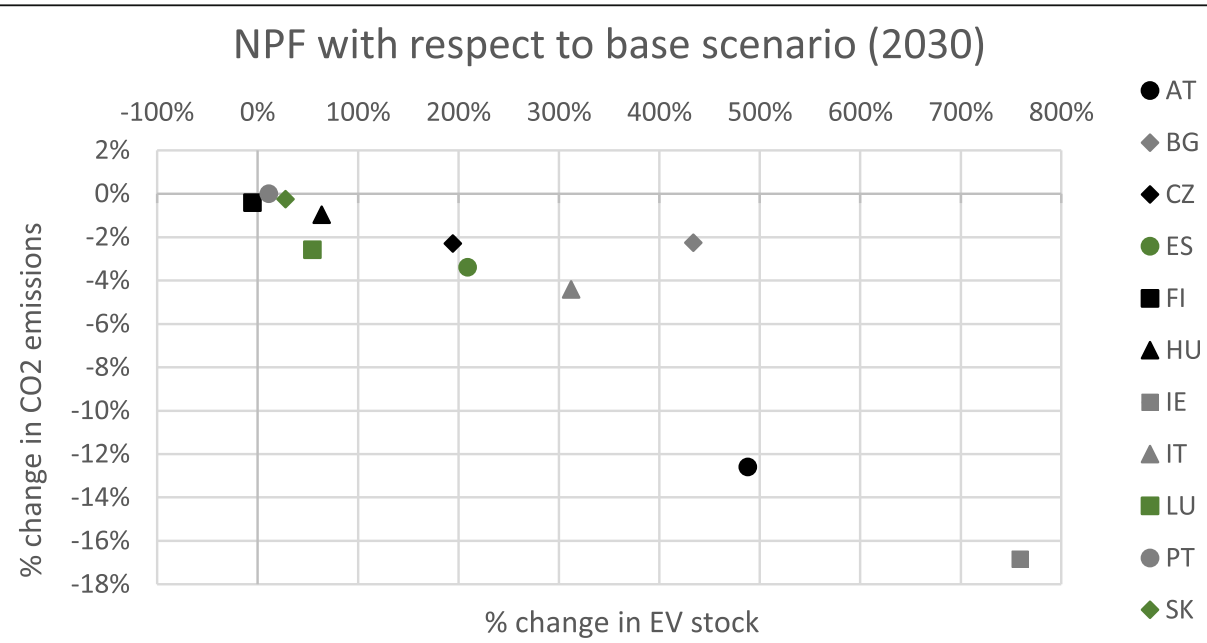

Fig. 7 Changes in $\mathrm{EV}$ stock versus $\mathrm{CO}_{2}$ emissions between scenarios in 2030 


\section{NPF with respect to base scenario (2030)}

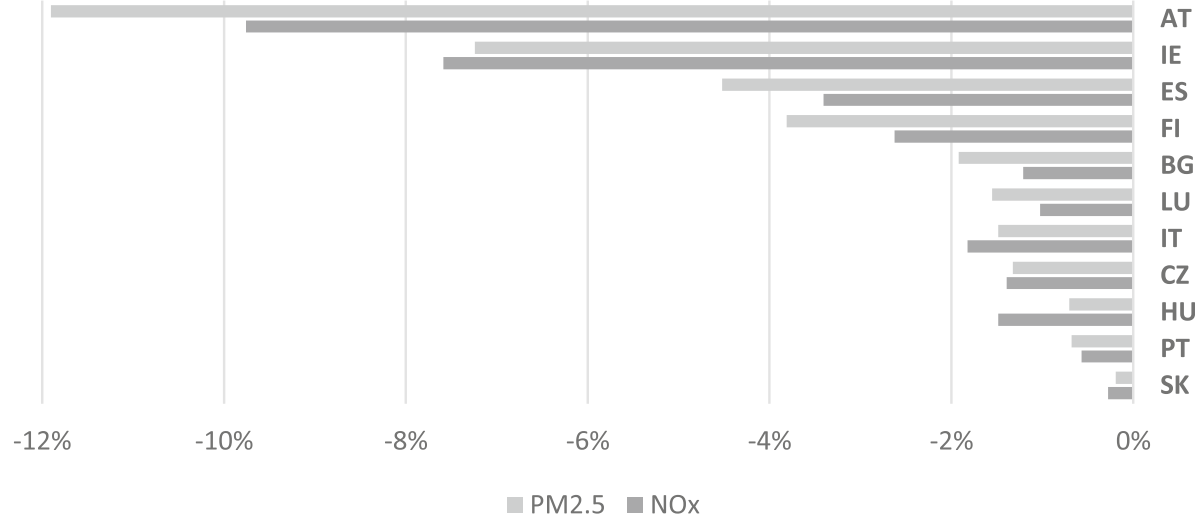

Fig. 8 Changes in air pollutant emissions between scenarios in 2030

respectively, urban background concentrations of $\mathrm{NO}_{2}$ and $\mathrm{PM}_{2.5}$. In both $\mathrm{NO}_{2}$ and $\mathrm{PM}_{2.5}$ modelling, baseline total emissions (not only from traffic) are initially considered, then analysing how the change in transport emissions (considering only reductions of exhaust emissions, and no change in tyre, break and road wear emissions from EVs) affect concentrations. Indeed the maps show only the impact on concentrations due to traffic policies, but (to be able to properly simulate air quality) all other emissions (from the other sectors, as from agriculture, residential heating, etc.) are taken into account.
In terms of $\mathrm{NO}_{2}$ concentrations, the largest reductions (up to 1\%) with respect to the base are simulated to occur in AT, DE and FR in 2020 (map on the left in Fig. 9). In 2030, the greatest improvements in $\mathrm{NO}_{2}$ concentrations of up to $6 \%$ can be found in $\mathrm{AT}$ and IE (map on the right in Fig. 9). Concerning $\mathrm{PM}_{2.5}$ concentrations, the pattern is similar in the sense that the greatest reductions can be found in the same countries, for both years (Fig. 10). However, differences between the two pollutants emerge: whereas $\mathrm{NO}_{2}$ tends to be concentrated along road links, $\mathrm{PM}_{2.5}$ appears to be concentrated

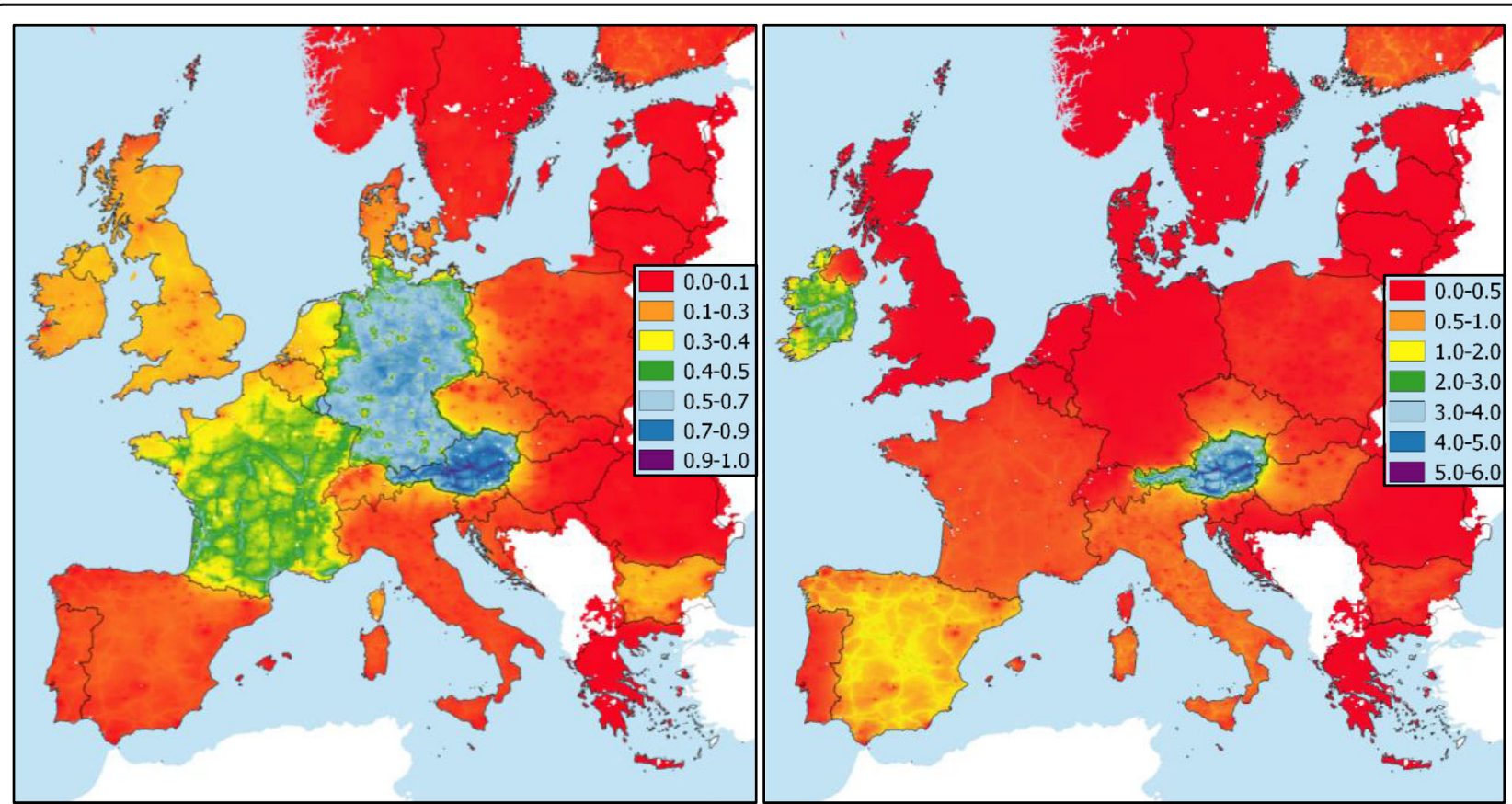

Fig. $9 \mathrm{NO}_{2}$ concentration reductions [\%] in 2020 [left] and 2030 [right] (in the NPF scenario with respect to the base scenario). Source: based on EU [22]. Legend: note the change in scale 


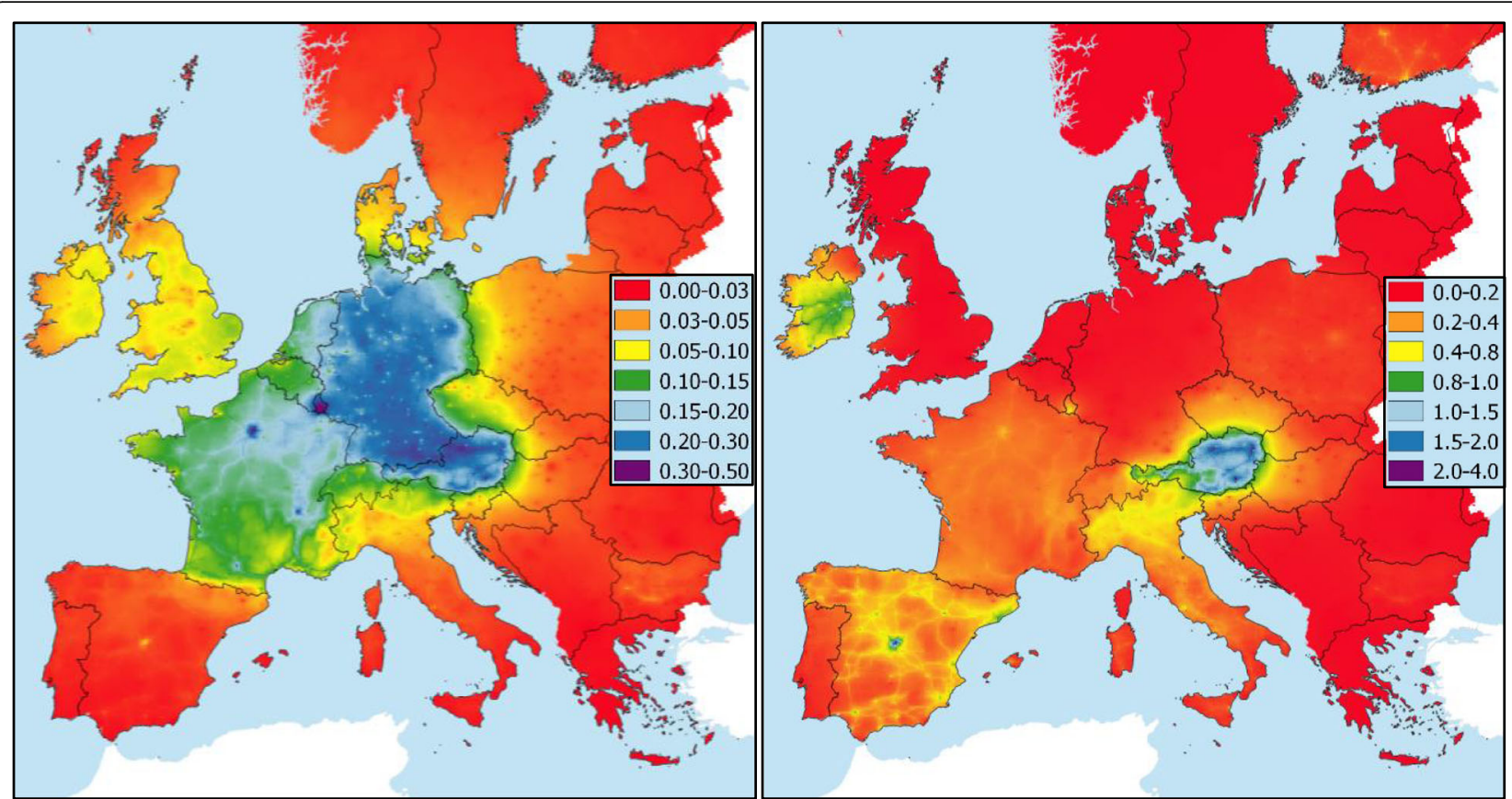

Fig. $10 \mathrm{PM}_{2.5}$ concentration reductions [\%] in 2020 [left] and 2030 [right] (in the NPF scenario with respect to the base scenario). Source: based on EU [22]. Legend: note the change in scale

around urban areas but more dispersive at this level of spatial aggregation. In particular, Switzerland seems to benefit in the simulation from lower levels of $\mathrm{PM}_{2.5}$ concentrations as a result of EV market uptake in its neighbouring countries. The maximum relative reduction in $\mathrm{PM}_{2.5}$ concentrations with respect to the base is $0.5 \%$ in 2020 and $4 \%$ in 2030.

As expected (cf. Section 4.2), there are no differences in the values of the environmental indicators between both scenarios for EL, HR, MT, RO, SE and SI. This is also visible in the maps (with the exception of MT due to their size), which show zero changes (i.e. in red) for these countries. Again, due to the aforementioned dispersive effect, some of these countries (particularly SI) seem to benefit from $\mathrm{PM}_{2.5}$ concentration reductions (Fig. 10).

\section{Conclusions and further research}

Ambitious GHG emission and air pollutant emission and concentration reductions in the transport sector require sound policies that facilitate the market deployment of low- and zero-emission vehicle technologies. Given the uncertainty that surrounds the market uptake of EVs, in this study two scenarios were constructed and, after calibration, calculated in the DIONE model. Their impacts on five environmental indicators (tailpipe $\mathrm{CO}_{2}, \mathrm{NO}_{\mathrm{x}}$ and $\mathrm{PM}_{2.5}$ emissions as well as urban background $\mathrm{NO}_{2}$ and $\mathrm{PM}_{2.5}$ concentrations) were modelled and presented. Whereas the base scenario drew on the PRIMES-TREMOVE output for an adapted version of the EU Reference Scenario 2016, the NPF scenario was the result of quantifying the effect of the Directive (2014/94/EU) on the European countries that communicated future EV stock estimates in their NPFs.

Due to the growth trend in car travel demand at the EU28 level projected in the EU Reference Scenario, in the base scenario the total reductions in $\mathrm{CO}_{2}$ emissions between 2015 and 2030 are lower (13\%) than those that could be achieved on a per car basis (21\%) (i.e. if the 2030 value of the average annual vehicle- $\mathrm{km}$ travelled by car remained at the same level as the 2015 value).

The NPF scenario leads to higher emission reductions, when compared with a scenario that does not take incentives for alternative fuels into account (i.e. base scenario). When put into perspective with the GHG emissions mitigation goals highlighted in the introduction, the simulated level of $\mathrm{CO}_{2}$ emissions from $\mathrm{EU}$ cars in 2030 under the NPF scenario remains relatively high. This would entail that substantial mitigation efforts would still be needed beyond 2030 to meet the 2050 transport mitigation target. Based on our simulations, it can be expected that countries with a higher level of ambition will achieve higher reductions in GHG emissions 
and concentrations of air pollutants. In this work, only two countries (AT, IE) achieved $\mathrm{CO}_{2}$ emission reductions greater than $10 \%$. These same two countries also achieved, as per our simulations, the greatest $\mathrm{PM}_{2.5}$ and $\mathrm{NO}_{\mathrm{x}}$ emission reductions with consequently the greatest reductions of $\mathrm{PM}_{2.5}$ and $\mathrm{NO}_{2}$ concentrations with positive effects on health.

Notwithstanding, a higher level of ambition does not necessarily translate into attainment of the EV stock estimates envisioned by the NPFs. For that, policy measures supporting EV uptake are needed. These were indeed stated in most of the NPFs assessed, but their contribution to realising the future EV stock estimates has not been analysed in this paper. Further research will revolve around the analysis not only of those measures, and on whether they are consistent with the emission reductions simulated here, but also consider recent announcements of future bans on conventional car sales.

The main limitation of this study was data availability. Article 10(1) of the Directive requires that Member States submit a report on the implementation of their NPFs in late 2019. Annex I of the Directive states that one element of the report is 2020, 2025 and 2030 alternative fuel vehicles estimates. Because of these requirements and as progress in the field of electro-mobility is being made, we expect the datasets contained in those implementation reports to be more comprehensive than the ones used in this work. This would allow a more robust analysis at the EU level. As stated in Section 4, the scenario method was adopted to cope with uncertainty but we do not claim we have covered the possibility space with the two scenarios presented in this paper. In fact, there was overall limited difference between scenarios. Furthermore, undertaking a scenario construction exercise tackles only one level of uncertainty. To account for uncertainty within each scenario, additional techniques such as sensitivity analysis [31] via Monte Carlo simulation are available. A promising starting point for such analysis would be to test the assumptions listed in Table 4, which may also be revisited in future work as new information becomes available.

A second limitation arises from the model differences between PRIMES-TREMOVE and DIONE, which required several assumptions. These in turn strongly influenced the results of the whole modelling exercise. Further work to address this issue in DIONE could be undertaken.

The third limitation concerns the adoption of emission factors and system boundary. This study focused on tailpipe or tank-to-wheel emissions. Specifically, real-world $\mathrm{CO}_{2}$ emissions, not New European
Driving Cycle type approval, were calculated. However, recent evidence using an alternative measurement method suggests that $\mathrm{NO}_{\mathrm{x}}$ emissions from diesel cars are notably higher than previously estimated (see [2]) and used in this study. In addition to tailpipe, vehicle non-exhaust and well-to-tank emissions (see $[13,39,50]$ ) could be further researched. An even wider system boundary would also consider car manufacturing and scrappage, including battery-related, emissions (see Samaras and Meisterling [45] and Notter et al. [41]). A comprehensive lifecycle analysis is expected to shed more light into the actual environmental impacts of a more diversified car stock in Europe. A recent step in this direction is EEA [16], which reports not only human health impacts from EVs, such as toxicity, but also ecosystem impacts such as freshwater eutrophication (see also Hawkins et al. [33]). In terms of job impacts, see Thiel et al. [49].

Finally, travel behavioural changes have not been addressed in this work. It is desirable to carry out further research on the implications of autonomous cars as well as on the potential for reducing car ownership levels (through e.g. shared mobility) and for increasing public transport ridership in Europe.

\section{Appendix}

Despite having aligned the car travel demand and car stock values between both models, there was still some discrepancy in the variable energy demand (Fig. 11). In this exercise, energy demand refers to tank-to-wheel (i.e. direct) and is measured in kilotonnes of oil equivalent (ktoe). As can be seen, the update of DIONE to car travel demand and car stock according to the EU Reference Scenario 2016 improves the match between both models for energy demand but it is not as close to $100 \%$ as was the case for other variables (cf. Fig. 2). To get closer (we found satisfactory for our purposes to tolerate a match above 90\%), a second correction was made by adjusting the efficiency values of cars.

As outlined in Section 4.2, an alternative approach to deal with the second group of countries was to assume constant EV stock beyond the last reported value. This is represented by the 'dummy NPF scenario', as illustrated for BE in Fig. 12.

As explained in Section 5, the remarkable results for FI can be traced to the assumption that determines the proportions of PHEVs, BEVs and FCEVs within the EV stock, justified in Section 4.2. In the particular case of FI, Fig. 13 shows that the share of BEVs is systematically larger in the NPF scenario than in the base scenario. 


\section{Energy demand from cars (EU28)}

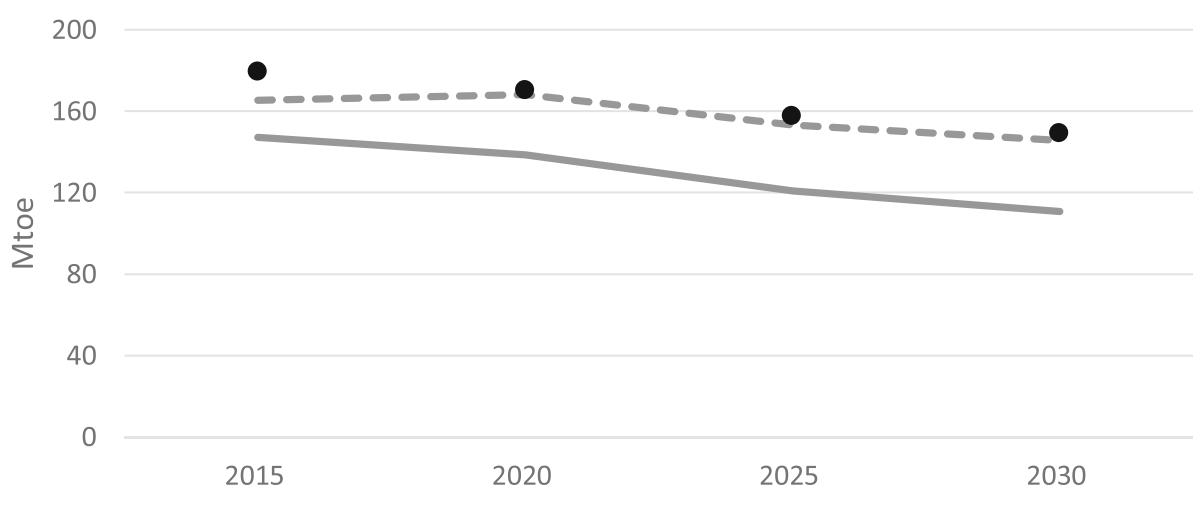

- PRIMES-TREMOVE DIONE (before) - - DIONE (after)

Fig. 11 Energy demand (EU28) in PRIMES-TREMOVE and DIONE, before and after correction

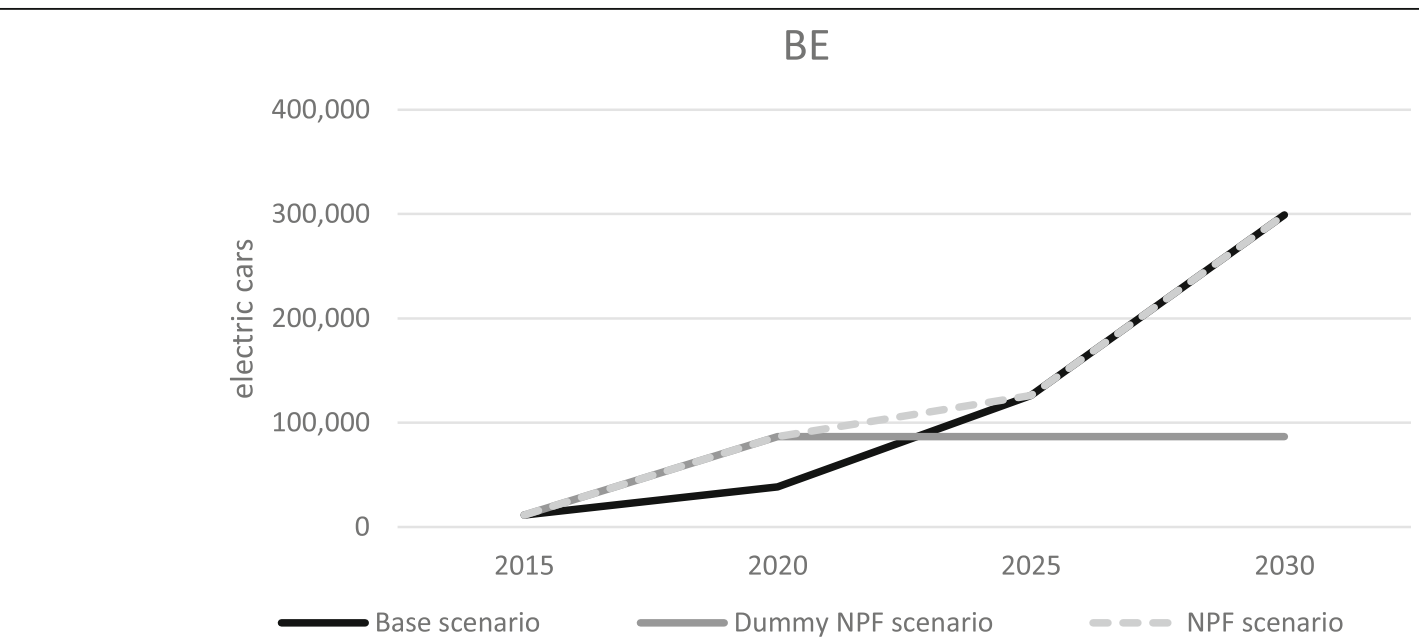

Fig. 12 EV stock (BE) under different scenarios

\section{$\mathrm{FI}$}

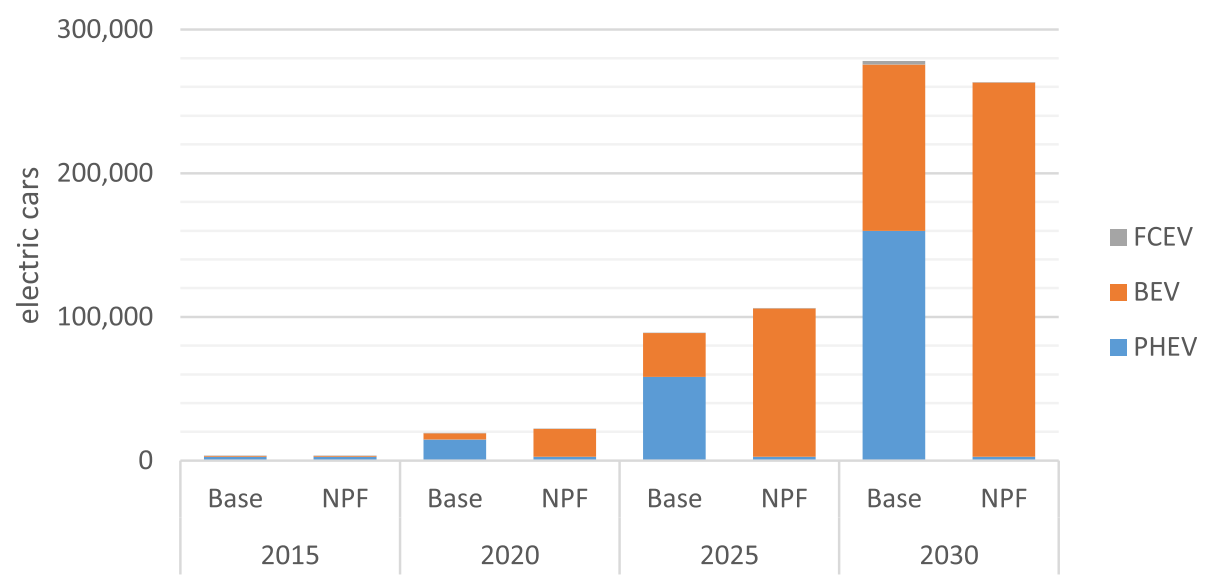

Fig. 13 EV stock $(F I)$, by powertrain 


\section{Additional file}

Additional file 1: Research data. (XLSX $8 \mathrm{~kb})$

\section{Acknowledgements}

We are very grateful to Marko Horvat and Martin Dolinsky for their support in running some of the simulations; Beatriz Acosta Iborra, Marek Bielewski, Nerea De Miguel Echevarria and Pietro Moretto for helping us assess the NPFs as well as Antonio Tricas Aizpun, Axel Volkery, Maria Cristina Mohora, Matteo Ordinanovich and Rolf Diemer for providing comments on an earlier version of the manuscript. We are also very grateful to two anonymous reviewers for their comments, which helped us improve the manuscript.

\section{Authors' contributions}

CT conceptualised the scenarios and supervised the work. JGV drafted the original manuscript and generated the DIONE output. PS generated the PRIMES-TREMOVE output. EPe and Epi generated the SHERPA output. AJ produced the maps. AJ, CT, JGV and JK assessed the NPFs. All authors read and approved the final manuscript.

\section{Authors' information}

JGV works as a technical officer - scientific researcher in the Sustainable Transport Unit, Joint Research Centre (JRC) of the European Commission. He worked as a researcher at the Chair of Energy Economics of the Institute for Industrial Production (IIP), Karlsruhe Institute of Technology (KIT). He holds a Masters in Transport Economics from the Institute for Transport Studies, University of Leeds. His doctoral thesis was entitled "The impact of electric cars on oil demand and greenhouse gas emissions in key markets". AJ works as a Scientific Project Officer in the Sustainable Transport Unit, Directorate Energy, Transport and Climate, at the JRC of the European Commission. In 2013, she joined JRC as a Post-doctoral GrantHolder within the Institute for the Protection and Security of the Citizen, Global Security and Crisis Management Unit. She graduated in Electrical Engineering and Computer Science from the Polytechnic University of Bucharest (PUB) Romania, in 2005. She received a Master degree in Image Processing and Artificial Intelligence from PUB in 2007 and a PhD degree in Electronics, Telecommunication and Computer Science from PUB and Grenoble University (France), in 2011.

EPe works as scientific / technical project officer in the Air and Climate Unit, JRC of the European Commission. She holds a Master degree in Nuclear Engineering from Politecnico Milano (Italy) and a Master degree in Energy and Mineral Engineering from The Pennsylvania State University (USA). She obtained a Ph.D. in the Doctoral Program for Energy from École Polytechnique Fédérale de Lausanne (Switzerland). EPi works as a scientific / technical project officer in the Air and Climate Unit, JRC of the European Commission. He graduated in Environmental Engineering from the Politecnico Milano in 2002, and obtained a Ph.D. in Information Engineering from the University of Brescia in 2007. His research interests include modelling and simulation of nonlinear systems, system identification and optimisation techniques. He is mainly concerned with air quality applications, considering monitoring, forecasting and planning. JK has more than 10 years of experience in research on the economics of transport and energy. Before joining the Sustainable Transport Unit of the European Commission's JRC in 2014, she worked as a researcher at Potsdam Institute for Climate Impact Research, Germany, and as a policy consultant. JK holds a Ph.D. and a Master in Economics, both awarded by the University of Potsdam, Germany. She studied economics and social sciences at University Cologne, Germany, Sciences Po Paris, France, and University of Potsdam, Germany.

PS is coordinating the activities of the Transport Group within the Energy Economy-Environment Modelling Lab of National Technical University of Athens. PS has 10 years of experience in the field of applied energy and transport economic policy analysis. He manages projects related to the use of the PRIMES-TREMOVE model for the transport sector, leads new model developments and conducts policy relevant quantitative research. Pelopidas Siskos holds an engineering (BSC and MSc) degree and a PhD in energy and transport economics.

$\mathrm{CT}$ is the head of the Energy Efficiency and Renewables Unit at the Directorate for Energy, Transport and Climate, JRC of the European Commission. Before joining the European Commission, he worked for 12 years in the European Engineering Centre of Opel. He holds a Doctoral degree (Dr.nat.techn.) from the
University of Natural Resources and Life Sciences Vienna, a Masters degree in Environmental Science (Geooekologie) from the Technical University Braunschweig, a bachelor's degree in Biology from Université Paris VI and an undergraduate degree in Economics from the University Frankfurt (Main).

\section{Funding}

There was no funding.

\section{Availability of data and materials}

The datasets generated and/or analysed during the current study are available in the Additional file 1 repository.

\section{Competing interests}

The views expressed are purely those of the authors and may not in any circumstances be regarded as stating an official position of the European Commission. Otherwise, the authors declare that they have no competing interests.

\section{Author details}

${ }^{1}$ European Commission, Joint Research Centre (JRC), Via E. Fermi, 2749 Ispra, VA, Italy. ${ }^{2}$ Department of Electrical and Computer Engineering, Energy-Economy-Environment Modelling Laboratory (E3M-Lab), National Technical University of Athens, 9 Iroon Politechniou Street, 15773 Zografou Campus, Athens, Greece.

Received: 29 January 2019 Accepted: 11 July 2019

Published online: 20 August 2019

\section{References}

1. Automotive News (2018). WW, Mercedes, Porsche stop plug-in hybrid sales on new WLTP emissions rules. Automotive News Europe [WWW document] URL http://europe.autonews.com/article/20180927/ANE/180929899/vwmercedes-porsche-stop-plug-in-hybrid-sales-on-new-wltp-emissions. Accessed 22 Dec 2018

2. Bernard, Y., Tietge, U., German, J., \& Muncrief, R. (2018). Determination of real-world emissions from passenger vehicles using remote sensing data. The True Initiative.

3. Capros, P., Kannavou, M., Evangelopoulou, S., Petropoulos, A., Siskos, P., Tasios, N., Zazias, G., \& DeVita, A. (2018). Outlook of the EU energy system up to 2050: The case of scenarios prepared for European Commission's "clean energy for all Europeans" package using the PRIMES model. Energy Strategy Reviews, 22, 255-263. https://doi.org/10.1016/j.esr.2018.06.009.

4. Capros, P., Tasios, N., De Vita, A., Mantzos, L., \& Paroussos, L. (2012). Modelbased analysis of decarbonising the EU economy in the time horizon to 2050. Energy Strategy Reviews, 1, 76-84. https://doi.org/10.1016/j.esr.2012.06. 003 European Energy System Models.

5. Clappier, A., Pisoni, E., \& Thunis, P. (2015). A new approach to design source-receptor relationships for air quality modelling. Environmental Modelling \& Software, 74, 66-74. https://doi.org/10.1016/j.envsoft.2015.09. 007.

6. Dieckhoff, C. (2011). Energieszenarien: Konstruktion, Bewertung und Wirkung "Anbieter" und "Nachfrager" im Dialog. Karlsruhe: KIT Scientific Publishing.

7. DOE. (2017). Progress in hydrogen and fuel cells. Karlsruhe: Office of Energy Efficiency \& Renewable Energy. U.S. Department of Energy (DOE).

8. Düring, I., Bächlin, W., Ketzel, M., Baum, A., Friedrich, U., \& Wurzler, S. (2011). A new simplified NO/NO2 conversion model under consideration of direct NO2-emissions. Meteorologische Zeitschrift, 20,67-73. https://doi.org/10.112 7/0941-2948/2011/0491.

9. E3MLab. (2015). PRIMES MODEL 2013-2014. Detailed model description. E3MLab/Institute of Communication and Computer Systems (ICCS) at National Technical University of Athens [WWW document]. URL https://ec. europa.eu/clima/sites/clima/files/strategies/analysis/models/docs/primes_ model_2013-2014_en.pdf. Accessed 30 Apr 2019.

10. EAFO (2018). European alternative fuels observatory [WWW document]. URL http://www.eafo.eu/. Accessed 22 Dec 2018.

11. EC. (2018). In-depth analysis in support of the Commission Communication COM(2018) 773: A clean planet for all - a European long-term strategic vision for a prosperous, modern, competitive and climate neutral economy. Karlsruhe: European Commission

12. EC. (2016). EU reference scenario 2016. Energy, transport and GHG emissions trends to 2050. Karlsruhe: European Commission. 
13. Edwards, R., Hass, H., Larivé, J.-F., Lonza, L., Maas, H., \& Rickeard, D. (2014). WELL-TO-WHEELS report version 4.a : JEC WELL-TO-WHEELS ANALYSIS (EUR scientific and technical research reports). Karlsruhe: Publications Office of the European Union

14. EEA. (2019). Size of the vehicle fleet. Dieselisation. European Environment Agency (EEA) [WWW document]. URL https://www.eea.europa.eu/data-andmaps/indicators/size-of-the-vehicle-fleet/size-of-the-vehicle-fleet-9. Accessed 30 Apr 2019.

15. EEA. (2018a). Air quality in Europe - 2018 report. EEA report no 12/2018. Karlsruhe: European Environment Agency (EEA).

16. EEA. (2018b). Electric vehicles from life cycle and circular economy perspectives. TERM 2018: Transport and Environment Reporting Mechanism (TERM) report. Karlsruhe: European Environment Agency (EEA).

17. EEA. (2017a). Greenhouse gas emissions from transport. European Environment Agency [WWW document]. URL https://www.eea.europa.eu/ data-and-maps/indicators/transport-emissions-of-greenhouse-gases/ transport-emissions-of-greenhouse-gases-10. Accessed 22 Dec 2018.

18. EEA. (2017b). Air quality in Europe 2017. Karlsruhe: European Environment Agency (EEA).

19. EEA. (2016). Premature deaths attributable to air pollution. Karlsruhe: European Environment Agency (EEA).

20. EMISIA (2017). COPERT [WWW document]. https://www.emisia.com/utilities/ copert/. Accessed 22 Dec 2018

21. e-Mobil BW. (2013). Wasserstoff-Infrastruktur für eine nachhaltige Mobilität: Entwicklungsstand und Forschungsbedarf. Karlsruhe: Landesagentur für Elektromobilität und Brennstoffzellentechnologie Baden-Württemberg (emobil BW).

22. EU (2017). Commission Staff Working Document detailed assessment of the National Policy Frameworks accompanying the document Communication from the Commission to the European Parliament, the Council, the European Economic and Social Committee and the Committee of the Regions towards the broadest use of alternative fuels - an action plan for alternative fuels infrastructure under Article 10(6) of Directive 2014/94/EU, including the assessment of national policy frameworks under Article 10(2) of Directive 2014/94/EU [WWW document]. URL http://eur-lex.europa.eu/ legal-content/EN/TXT/?qid=1512384850915\&uri=CELEX:52017SC0365. Accessed 22 Dec 2018.

23. EU (2016). Communication from the Commission to the European Parliament, the Council, the European Economic and Social Committee and the Committee of the Regions. A European strategy for low-emission mobility. European Union Law [WWW Document]. URL http://eur-lex.europa. eu/legal-content/en/ALL/?uri=CELEX:52016DC0501. Accessed 22 Dec 2018.

24. EU (2014). Directive 2014/94/EU of the European Parliament and of the Council of 22 October 2014 on the deployment of alternative fuels infrastructure. European Union Law [WWW document]. URL http://eur-lex. europa.eu/legal-content/EN/TXT/?uri=celex\%3A32014L0094. Accessed 22 Dec 2018.

25. EU (2013). Commission Staff Working Document Impact Assessment accompanying the document proposal for a directive on the deployment of alternative fuels infrastructure [WWW Document]. URL https://eur-lex.europa.eu/legal-content/en/TXT/?uri=CELEX:52013SC0005. Accessed 30 Apr 2019.

26. EU. (2011). WHITE PAPER roadmap to a single European transport areaTowards a competitive and resource efficient transport system. European Union Law [WWW Document]. URL http://eur-lex.europa.eu/legal-content/ EN/ALL/?uri=CELEX:52011DC0144. Accessed 22 Dec 2018.

27. EU (2009). Directive 2009/30/EC of the European Parliament and of the Council of 23 April 2009 amending Directive 98/70/EC as regards the specification of petrol, diesel and gas-oil and introducing a mechanism to monitor and reduce greenhouse gas emissions and amending Council Directive 1999/32/EC as regards the specification of fuel used by inland waterway vessels and repealing Directive 93/12/EEC. European Union Law [WWW Document]. URL https://eur-lex.europa.eu/legal-content/EN/TXT/ ?uri=celex\%3A32009L0030. Accessed 30 Apr 2019

28. Eurostat (2019). Your key to European statistics. European Commission. [WWW Document]. URL http://ec.europa.eu/eurostat/web/main/home. Accessed 30 Apr 2019.

29. EVI. (2018). Global EV Outlook 2018. Towards cross-modal electrification. Electric Vehicles Initiative (EVI). Karlsruhe: International Energy Agency (IEA)

30. GeM (2017). Green eMotion (GeM) project [WWW Document]. URL http:// www.greenemotion-project.eu/. Accessed 22 Dec 2018.
31. Hamby, D. M. (1994). A review of techniques for parameter sensitivity analysis of environmental models. Environmental Monitoring and Assessment, 32, 135-154. https://doi.org/10.1007/BF00547132.

32. Harrison, G., Krause, J., \& Thiel, C. (2016). Transitions and impacts of passenger car powertrain technologies in European member states. Transportation Research Procedia, 14, 2620-2629. https://doi.org/10.1016/j. trpro.2016.05.418 Transport Research Arena TRA2016.

33. Hawkins, T. R., Singh, B., Majeau-Bettez, G., \& Strømman, A. H. (2012). Comparative environmental life cycle assessment of conventional and electric vehicles. Journal of Industrial Ecology, 17, 53-54. https://doi.org/1 0.1111/j.1530-9290.2012.00532.x.

34. Hyundai (2018). Modelle. Hyundai Motor Deutschland GmbH [WWW Document]. URL https://www.hyundai.de/. Accessed 22 Dec 2018

35. IIASA. (2019). Greenhouse gas - air pollution interactions and synergies (GAINS) model. International Institute for Applied Systems Analysis (IIASA) [WWW document]. URL http://gains.iiasa.ac.at/models/index.html. Accessed 30 Apr 2019.

36. Ionity (2019). News \& media. Fast charging station network starts to take shape [WWW document]. https://ionity.eu/en/news-and-media.html. Accessed 22 Dec 2018.

37. Krause, J., Donati, A. V., Thiel, C. (2017). Light duty vehicle CO2 emission reduction cost curves and cost assessment - the DIONE model. JRC science for policy report. Joint Research Centre (JRC), European Commission [WWW document]. URL http://publications.jrc.ec.europa.eu/repository/bitstream/ JRC108725/kjna28821enn.pdf. Accessed 30 Apr 2019.

38. Krook-Riekkola, A., Berg, C., Ahlgren, E. O., \& Söderholm, P. (2017). Challenges in top-down and bottom-up soft-linking: Lessons from linking a Swedish energy system model with a CGE model. Energy, 141, 803-817. https://doi. org/10.1016/j.energy.2017.09.107.

39. Moro, A., \& Lonza, L. (2017). Electricity carbon intensity in European member states: Impacts on GHG emissions of electric vehicles. Transportation Research Part D: Transport and Environment. https://doi.org/10.1016/j.trd.2017.07.012.

40. Nitta, N., Wu, F., Lee, J. T., \& Yushin, G. (2015). Li-ion battery materials: Present and future. Materials Today, 18, 252-264. https://doi.org/10.1016/j. mattod.2014.10.040.

41. Notter, D. A., Gauch, M., Widmer, R., Wäger, P., Stamp, A., Zah, R., \& Althaus, H.-J. (2010). Contribution of li-ion batteries to the environmental impact of electric vehicles. Environmental Science \& Technology, 44, 6550-6556. https:// doi.org/10.1021/es903729a.

42. Nykvist, B., \& Nilsson, M. (2015). Rapidly falling costs of battery packs for electric vehicles. Nature Climate Change, 5, 329-332. https://doi.org/10.1038/ nclimate2564.

43. Pisoni, E., Clappier, A., Degraeuwe, B., \& Thunis, P. (2017). Adding spatial flexibility to source-receptor relationships for air quality modeling. Environmental Modelling \& Software, 90,68-77. https://doi.org/10.1016/j.envsoft.2017.01.001.

44. QGIS (2017). The QGIS project. [WWW document]. URL https://www.qgis. org/en/site/. Accessed 30 Apr 2019

45. Samaras, C., \& Meisterling, K. (2008). Life cycle assessment of greenhouse gas emissions from plug-in hybrid vehicles: Implications for policy. Environmental Science \& Technology, 42, 3170-3176. https://doi.org/10.1021/ es702178s.

46. Siskos, P., Capros, P., \& De Vita, A. (2015). $\mathrm{CO}_{2}$ and energy efficiency car standards in the EU in the context of a decarbonisation strategy: A modelbased policy assessment. Energy Policy, 84, 22-34. https://doi.org/10.1016/j. enpol.2015.04.024.

47. Siskos, P., Zazias, G., Petropoulos, A., Evangelopoulou, S., \& Capros, P. (2018). Implications of delaying transport decarbonisation in the EU: A systems analysis using the PRIMES model. Energy Policy, 121, 48-60. https://doi.org/1 0.1016/j.enpol.2018.06.016

48. Thiel, C., Drossinos, Y., Krause, J., Harrison, G., Gkatzoflias, D., \& Donati, A. V. (2016). Modelling electro-mobility: An integrated modelling platform for assessing European policies. Transportation Research Procedia, 14, 2544-2553. https://doi.org/10.1016/j.trpro.2016.05.341 Transport Research Arena TRA2016.

49. Thiel, C., Julea, A., Acosta Iborra, B., De Miguel Echevarria, N., Peduzzi, E., Pisoni, E., Gómez Vilchez, J.J., Krause, J. (2019). Assessing the impacts of electric vehicle recharging infrastructure deployment efforts in the European Union. Energies, 12, 2409. https://doi.org/10.3390/en12122409.

50. Thiel, C., Nijs, W., Simoes, S., Schmidt, J., van Zyl, A., \& Schmid, E. (2016). The impact of the EU car CO2 regulation on the energy system and the role of electro-mobility to achieve transport decarbonisation. Energy Policy, 96, 153166. https://doi.org/10.1016/j.enpol.2016.05.043. 
51. Thunis, P., Clappier, A., Pisoni, E., \& Degraeuwe, B. (2015). Quantification of non-linearities as a function of time averaging in regional air quality modeling applications. Atmospheric Environment, 103, 263-275. https:/doi. org/10.1016/j.atmosenv.2014.12.057.

52. Thunis, P., Degraeuwe, B., Pisoni, E., Ferrari, F., \& Clappier, A. (2016). On the design and assessment of regional air quality plans: The SHERPA approach Journal of Environmental Management, 183, 952-958. https://doi.org/10.1 016/j.jenvman.2016.09.049.

53. Thunis, P., Pisoni, E., Degraeuwe, B., Kranenburg, R., Schaap, M., \& Clappier, A. (2015). Dynamic evaluation of air quality models over European regions. Atmospheric Environment, 111, 185-194. https://doi.org/10.1016/.atmosenv.2015.04.016.

54. TRACCS. (2019). Project overview. Transport data collection supporting the quantitative analysis of measures relating to transport and climate change (TRACCS). [WWW document] URL from https://traccs.emisia.com/index.php. Accessed 30 Apr 2019

55. Trombetti, M., Pisoni, E., Lavalle, C. (2017). Downscaling methodology to produce a high resolution gridded emission inventory to support local/city level air quality policies (EUR - Scientific and Technical Research Reports). Publications Office of the European Union. https://doi.org/10.2760/51058.

56. WW (2018). Elektro-mobilität: Modelle. Volkswagen (WW) [WWW Document]. https:/www.volkswagen.de/elektromobilitaet/de.html. Accessed 22 Dec 2018.

57. Zheng, M., Reader, G. T., \& Hawley, J. G. (2004). Diesel engine exhaust gas recirculation--A review on advanced and novel concepts. Energy Conversion and Management, 45, 883-900. https://doi.org/10.1016/S01968904(03)00194-8.

\section{Publisher's Note}

Springer Nature remains neutral with regard to jurisdictional claims in published maps and institutional affiliations.

\section{Submit your manuscript to a SpringerOpen ${ }^{\circ}$ journal and benefit from:}

- Convenient online submission

- Rigorous peer review

- Open access: articles freely available online

High visibility within the field

- Retaining the copyright to your article

Submit your next manuscript at $\boldsymbol{\nabla}$ springeropen.com 